NBER WORKING PAPER SERIES

\title{
CAN IRON-FORTIFIED SALT CONTROL ANEMIA? EVIDENCE FROM TWO EXPERIMENTS IN RURAL BIHAR
}

\author{
Abhijit Banerjee \\ Sharon Barnhardt \\ Esther Duflo \\ Working Paper 22121 \\ http://www.nber.org/papers/w22121
}

\author{
NATIONAL BUREAU OF ECONOMIC RESEARCH \\ 1050 Massachusetts Avenue \\ Cambridge, MA 02138 \\ March 2016
}

\begin{abstract}
Banerjee and Duflo are from The Massachusetts Institute of Technology, Barnhardt is from the Indian Institute of Management Ahmedabad. For financial support, we thank the U.K. Department for International Development, the International Initiative for Impact Evaluation, the U.S. National Institutes of Health (P01AG005842), the International Food Policy Research Institute, and the MIT Department of Economics. For dedicated research assistance we are grateful to the team at J-PAL, including Urmi Bhattacharya, Shruti Bhimsaria, Anna George, Dwijo Goswami, Radhika Jain, Seema Kacker, Sweta Kumari, Francine Loza, Bastien Michel, Krutika Ravishankar, Prianthi Roy, Achill Rudolph, Laura Stilwell, Srinivasan Vasudevan, Niloufer Taber, Micah Villareal and dozens of survey specialists. Dr. Vandana Sharma provided medical expertise. Our partners at Tata Chemicals Limited made the distribution of DFS possible in rural Bihar. The National Institute of Nutrition (Hyderabad) provided ongoing assistance with the verification of iron and iodine content in salt samples. These studies can be found in the AEA RCT Registry (AEARCTR-0000010, AEARCTR-0000013). We thank Nel Druce for detailed comments on a DFID report that underlies the analysis in this paper. All errors are our own and the paper does not represent the views of DFID or any other organization. The views expressed herein are those of the authors and do not necessarily reflect the views of the National Bureau of Economic Research.
\end{abstract}

NBER working papers are circulated for discussion and comment purposes. They have not been peer-reviewed or been subject to the review by the NBER Board of Directors that accompanies official NBER publications.

(C) 2016 by Abhijit Banerjee, Sharon Barnhardt, and Esther Duflo. All rights reserved. Short sections of text, not to exceed two paragraphs, may be quoted without explicit permission provided that full credit, including $\odot$ notice, is given to the source. 
Can Iron-Fortified Salt Control Anemia? Evidence from Two Experiments in Rural Bihar Abhijit Banerjee, Sharon Barnhardt, and Esther Duflo

NBER Working Paper No. 22121

March 2016

JEL No. I0,I00,I1,O11

\begin{abstract}
$\underline{\text { ABSTRACT }}$
Iron deficiency anemia is frequent among the poor worldwide. While it can be prevented with the appropriate supplement or food fortification, these programs often do not consistently reach the poorest. This paper reports on the impact of a potential strategy to address iron deficiency anemia in rural areas: double fortified salt (DFS) - salt fortified with iron and iodine. We conducted a large-scale experiment in rural Bihar. In 200 villages, randomly selected out of 400, DFS was introduced at a price that was half the regular retail price for DFS. After two years, we find no evidence that either selling DFS in villages or providing it for free directly to households has an economically meaningful or statistically significant impact on hemoglobin, anemia, physical health, cognition or mental health. For the sales experiment, we can reject at the $95 \%$ level a reduction of 2.5 percentage points in the fraction anemic in the entire sample, and 3.7 percentage points among those who were previously anemic. Using an IV strategy, we find a statistically significant, though relatively small, increase in hemoglobin and reduction in the fraction anemic for adolescents, a subgroup that has responded well to supplements and fortification in earlier studies. These disappointing results are explained both by relatively low take up and by low impact of DFS even when consumed more regularly for the majority of the population.
\end{abstract}

Abhijit Banerjee

Department of Economics, E52-540

MIT

77 Massachusetts Avenue

Cambridge, MA 02139

and NBER

banerjee@mit.edu

Sharon Barnhardt

Indian Institute of Management - Ahmedabad

Vastrapur

Ahmedabad 380015

INDIA

barnhardt@iimahd.ernet.in
Esther Duflo

Department of Economics, E52-544

MIT

77 Massachusetts Avenue

Cambridge, MA 02139

and NBER

eduflo@mit.edu 


\section{Introduction}

Iron deficiency is believed to be the most common nutrient deficiency in the world today. While quantifying the number of affected people is difficult, the WHO estimates that 1.6 billion people are anemic (de Benoist et al. 2008), and that about half of these cases can be traced to iron deficiency (World Health Organization, 2001). Iron deficiency anemia is more common among populations with a diet low in animal proteins, and high in rice or in whole wheat with high phytate content (phytates reduce absorption) (Zijp et al., 2000). It is therefore a particularly serious issue in Asia and in South Asia, where this type of diet is common. In Indonesia, a large scale study of iron supplements found that 50 percent of women aged 15 and above and 40 percent of men sampled were anemic at baseline (Thomas et al., 2003) 1

Iron deficiency anemia (IDA) increases susceptibility to infection and increases the likelihood of experiencing weakness or fatigue (see Haas and Brownlie (2001) for a review of the medical evidence). It has been linked to low productivity in adults and slowing of cognitive and physical growth among children (Lozoff, 2007; Lozoff et al., 2006). Among pregnant women, severe anemia can result in low birth weight and child mortality (Stoltzfus, 2001). Lower hemoglobin levels in the elderly are associated with cognitive decline ( Peters et al., 2008$)$ and worse physical performance (Penninx et al., 2004).

While iron deficiency anemia has been recognized to be a serious public health problem in developing countries for several years, not much progress has been made against it. Systematic changes in diet seem to be less likely to achieve in the short run. The two alternatives to diet change are supplementation and food fortification.

The WHO recommends that countries with endemic anemia adopt costly large-scale weekly iron and folic acid supplementation programs for children and adolescents, and several countries have embarked on such efforts over the past decades (Chong et al. 2015). The largest and most comprehensive study to date of such a program is Thomas et al. (2006) which found a

$\overline{1}$ Using standard thresholds of $12 \mathrm{~g} / \mathrm{dL}$ for women and $13 \mathrm{~g} / \mathrm{dL}$ for men. 
large effect of an iron supplementation program (where each individual was given 120 milligram of iron per week) on anemia and hemoglobin rates for those who were anemic at baseline. That study also found increases in the labor supply of males who were anemic at baseline, and an increase in the earnings of self-employed males, as well as improved health (including mental health). Chong et al. (2015) set up a randomized encouragement intervention among 219 adolescents in Peru to measure the impact of such programs on test scores. Iron pills were made available free at a local health center, and randomly selected students were exposed to two versions of a short video that encouraged them to get the supplements. On average, students in the treatment groups received $80 \%$ more pills than students in the control group over 10 weeks and were about twice as likely to receive at least $600 \mathrm{mg}$ over 10 weeks (about a third of the recommended dietary allowance (RDA)). They found large reductions in anemia among treatment students who were previously anemic, and improvements in both cognitive test and performance at school.

These interventions suggests that iron supplements, if regularly taken, can be effective. However, Thomas et al. (2006) spent considerable resources insuring consistent take up. In Chong et al. (2015), without additional information (the control group), few adolescents took up the supplement which was available free in the local clinic and it took many videos to increase take up. Even with this encouragement, only $57 \%$ of the adolescents in the treatment groups took a dose considered to be sufficient to affect hemoglobin levels. While systematic supplementation seems like a feasible strategy in health centers or schools, this method faces issues with non-compliance, as well as supply, procurement, and distribution, since many countries lack the public health infrastructure to handle the logistics (Gillespie, 1998). Outside of these settings, systematic distribution of iron supplements may not be a practical policy in resource-poor settings, where the public health systems do not have the capacity to distribute these supplements reliably on a large scale.

Iron supplementation of foods is potentially an attractive alternative, and as such, has generated considerable policy excitement. It requires no additional effort on the part of the consumer and can be done relatively cheaply in centralized locations. Foods that can be fortified with iron include flour, milk products, fish sauce, and salt. In particular, salt seems to be an ideal product to fortify: it is ubiquitous, cheap, and generally purchased from stores. Adding iron to packaged iodized salt thus seems to be a promising way to increase iron intake and reduce 
IDA.

Double-fortified salt (DFS) was not commercially available in India until recently, due to technical difficulties in insuring the stability of both the iron and the iodine. In the mid 1990s, India's National Institute of Nutrition (NIN, Hyderabad) developed DFS, fortified with iron and iodine. Fortified with $1 \mathrm{mg}$ iron per gram of salt, DFS is estimated to provide about $30 \%$ of the RDA of iron (National Institute of Nutrition (India), 2005) when consuming $10 \mathrm{~g}$ salt per day regularly (Ranganathan and Sesikeran, 2008). NIN scientists first demonstrated the long-term safety of DFS in animal studies (Nair et al., 1998). They also established the stability and bioavailability of iron in DFS as well as the acceptability and effectiveness of DFS with school children and with tribal populations through small scale trials (Nair et al., 1998; Brahmam et al., 2000; Sivakumar et al., 2001).

In the last five years, NIN and the Indian Government have sought to encourage wider adoption of DFS. Since 2011, the NIN formulation of DFS can be manufactured by private companies through a license agreement requiring a certain percentage of production to be donated to charities, such as school meal programs. In 2012, India's Department of Women and Child Development directed states to use DFS in the national mid-day meal scheme (school lunches) and the Human Resource Development Ministry did the same for the Integrated Child Development Scheme (Mudur, 2013). Several manufacturers produce and market DFS, including Tata Chemicals Limited (TCL). TCL is one of the leading manufacturers of salt in India, and we used their DFS, branded as "Tata Salt Plus" for our study. The maximum retail price of Tata Salt Plus is ₹20 (rupees) per kg, making it a relatively low-cost iron source, but around twice the price of regular iodized salt. $2^{2}$

The reasoning behind the potential for food fortification is simple: the first premise is that, contrary to a change in diet or regular consumption of iron supplements, consuming iron-fortified food does not require an important behavioral change, and therefore should be easy for individuals. Hence, the take up of fortified food could easily be very high. The second premise is that regular intake would compensate for the fact that individuals would get less iron from the fortified foods than from iron pills, leading to reduced anemia, and positive health and productivity impact. Surprisingly, neither of the two premises has really been tested.

2 Tata Salt, which is the highest quality iodized salt available, and one of the most expensive, normally sells for ₹15 per kg. 
In particular, the nationwide policy to use DFS in school meals and the approval for retail sales have happened despite the lack of any large-scale efficacy trials of DFS: there have only been two rigorous, long-term effectiveness studies of the NIN formula of DFS in India, among women or children in carefully monitored environments, and the results are mixed. One experiment with schoolchildren found that hemoglobin was $0.7 \mathrm{~g} / \mathrm{dL}$ higher when residential schools used DFS in all of the meals they made for children (versus none). The study, however, suffered from $79 \%$ attrition, which the authors attribute mostly to graduation (Sivakumar et al., 2001). The other experiment, with a tribal population, found no significant impact on hemoglobin (Sivakumar et al. 2001). Other experiments using different formulations of DFS are more encouraging. Rajagopalan and Vinodkumar (2000) conducted an experiment with female tea pickers in India on remote estate. Hemoglobin increased from $9.27 \mathrm{~g} / \mathrm{dL}$ to $10.78 \mathrm{~g} / \mathrm{dL}$, and productivity increased when DFS was combined with deworming. Haas et al. (2014) studied 212 female tea pickers in India. Hemoglobin concentration at endline was $11.7 \mathrm{~g} / \mathrm{dL}$ in treatment and $11.5 \mathrm{~g} / \mathrm{dL}$ in control. In all cases, the consumption was carefully monitored, ensuring perfect compliance with the required dosage.

To fill this important gap between policy and evidence, this paper reports on two experiments that test each of these premises. For the sales experiment, we partnered with Tata Chemicals Ltd., a major manufacturer of salt with a well recognized brand name, to make double fortified salt available at the reduced price of ₹9 in shops in 200 randomly selected villages in Bihar ${ }^{3}$ In all of these villages, information campaigns were conducted, and in some of them, additional interventions took place to increase take up (in particular, an edutainment movie was screened in some villages, and shopkeepers were provided incentives to sell the salt in other(Banerjee et al., 2016). Take up was reasonably high: on average $42.5 \%$ of households in Sales villages ever tried DFS, and $14.5 \%$ were using it at the time of the endline survey, approximately 23 months after the product had been launched.

The second experiment was embedded in the sales experiment: in 62 villages where DFS was available in shops, we distributed a regular supply of DFS for free at home to a subset of households, randomly selected within each of the villages. Take up was higher among these

3 In Banerjee et al. (2013) we set up small scale, individual-level, randomized pricing experiment to determine the demand curve for DFS. We found that demand falls sharply at a price of ₹10 per kilogram, the price of the cheapest alternative branded salt. Just under a third of the households tried it at just below that price (₹9). 
households, although not 100\%: $61 \%$ of households were using it at the time of the survey, and $75 \%$ of households had been using it just before (many of the others had just recently run out). This allows us to test the impact of higher DFS availability on hemoglobin and anemia and our other endpoints. In what is, to our knowledge, the first large-scale efficacy trial of the product we compare individuals in households that were offered DFS for free at home to individuals in two control groups: households in the same villages who had the option to buy DFS (and were subjected to all the information campaigns in those villages), but where not getting for free. This simulates, for example, the policy of making free DFS available to households eligible for food rations when it is otherwise available, and households in control villages, who do not have access to DFS at any price.

Finally, we combine the two experiments and the entire sample to construct instrumental variable estimates of actual consumption of DFS. This gives us two instruments, availability of DFS via sales and free distribution.

Even focusing on those who were anemic at baseline (Thomas et al. (2006) and Chong et al. (2015) find no impact of supplementation on those who were not), we find no significant impact of availability of DFS through sales in the whole sample (the point estimate is $0.077 \mathrm{~g} / \mathrm{dL}$, with a $95 \%$ confidence interval of $(-0.03 ; 0.157)$. For free DFS, the point estimate for previously anemic when we compare free DFS recipients to households in control villages is $0.018 \mathrm{~g} / \mathrm{dL}$, with a confidence interval of $(-0.122 ; 0.146)$. In subsamples, we do find a significant positive impact of availability of the sales treatment for males (significant at $5 \%$ even after controlling for multiple hypothesis testing) and for children below 15 (significant at the $10 \%$ level after controlling for multiple hypothesis testing). But we don't find the same effect for the free DFS experiment. Overall, in the IV regressions, we cannot reject zero effect of DFS consumption for the entire sample or subgroups defined by gender. We find, however, sizable and significantly positive impact on $\mathrm{Hb}$ concentration (and, correspondingly, a reduction in anemia) among adolescents in the IV regressions, consistent with previous studies (Chong et al., 2015, Sivakumar et al., 2001). In the adolescent subgroup, hemoglobin is $0.410 \mathrm{~g} / \mathrm{dL}$ higher and anemia lower by 12 percentage points. For the anemic at baseline subgroup, the confidence interval is $(-0.227 ;+0.267)$, and we also cannot rule out no effect for the anemic at baseline when women and men are considered separately. The null effect of this formula is also consistent with the previous study of workers 
in a tribal area of Andhra Pradesh, India (Sivakumar et al., 2001).

Although these results are only obtained in one setting and probably would need to be replicated, they are not encouraging for the prospect of DFS as a way to control anemia in rural areas. We also briefly discuss the results of another experiment where we attempted to provide a simple technology to fortify flour at the local level, with equally disappointing results. This contrasts with the promising impact of direct iron supplementation in the two recent studies we reviewed, at least when sufficient take up can be achieved. The issue may be that to make a notable difference for most people (sufficient to perhaps sustain their interest in the product), the iron dose must be large enough. But to be safe (and avoid poisoning due to over-consumption of iron) the concentration of iron supplementation in the food must be limited. With a single source of fortified food, and a diet that continues to be low in iron, the fortification is perhaps insufficient to make enough of a difference for individuals to be willing to continue with purchasing the product. This of course further reduces impact, and ultimately makes the strategy non-viable.

\section{Experimental design}

This paper reports the results of two experiments conducted concurrently in Bihar. The main experiment studies sales, while a smaller experiment investigates the impact of distributing free DFS at home. Our primary outcome measurements are hemoglobin level and whether or not an individual is classified as being anemic. Physical fitness, cognition and mental health are important downstream outcomes.

\subsection{Double Fortified Salt}

The double-fortified salt used in this experiment was manufactured and distributed by TCL. It follows the formula established by the NIN and provides 40 micrograms of iodine and $1 \mathrm{mg}$ of iron per gram of salt. Consumption of 10 grams of salt is needed to obtain $10 \mathrm{mg}$ of iron per day, which is approximately $30 \%$ of the recommended daily value for Indian populations, though the exact recommendation is dependent on age and gender (Indian Council of Medical Research, 2009) 4

$4 \quad$ The WHO provides recommended iron intakes for populations with very low dietary intake of iron. For adult males the WHO recommends $27.4 \mathrm{mg} /$ day. For adult, non-menopausal females, this number is $58.8 \mathrm{mg} / \mathrm{day}$. 
DFS, therefore, is expected to increase hemoglobin among people who eat enough of the salt consistently; who do not suffer illnesses (parasites, malaria, etc.) or have any complementary micronutrient deficiencies (such as Vitamin C) severe enough to block iron absorption; and who are iron deficient. For a person from this population weighing about $60 \mathrm{kgs}$, hemoglobin is expected to rise $1 \mathrm{~g} / \mathrm{dL}$ over a nearly two-year period with a consistent consumption of 10 grams of DFS daily. Iron-deficiency anemia, therefore, would be expected to decrease for DFS consumers who are within $1 \mathrm{~g} / \mathrm{dL}$ from the anemia cutoff for their age-sex group at baseline.

\subsection{Experimental Design}

\section{Sampling frame}

We conduct our experiments in the Bhojpur district of Bihar. Our sampling frame is the list of villages and households compiled by the District Rural Development Agency, while updating the number of above and below poverty line households in 2010. Across Bhojpur, there were 999 villages on the list. We considered all villages with fewer than 50 households to be ineligible for inclusion in the experiment. We stratified by Block (an administrative unit smaller than the District) and then in each of eight blocks randomly selected 29 villages and in each of six blocks randomly selected 28 villages. This gave us a total of 400 study villages. Within each village, we randomly selected 15 households to be measurement households, for a total of 6,000 households in the baseline sample $5^{5}$

\section{Experiments}

Figure 1 summarizes the experimental design in a nutshell. First, we stratified by block and then randomly assigned half of the villages to treatment and half to control, totaling 200 Sales and 200 control villages. Control households were therefore not aware of the experiment and the treatment. In all "Sales" villages, we provided the option to stock Tata Salt Plus to all kirana shops that operated in the village and the Public Distribution (PDS) shop that served the village. Packets of DFS were clearly marked with the special research Maximum Retail Price of ₹9 per kg.

Stocking of the salt started in August 2012 and lasted through February 2015. A dedicated team took orders from shops and oversaw delivery to shops by TCL stockists. Over 30

$5 \quad$ Four additional households were surveyed at baseline due to independent, unnecessary replacements. They were kept in the studies and the individuals in all 6,004 households were included in the baseline. 
months of stocking, there were a few instances in which PDS store operators who served both treatment and control villages indicated that they wished to also buy the salt for shops in control villages. They were refused and told that Tata Salt Plus was being sold using a lottery system, and that those shops had not been selected.

TCL launched the product in Sales villages using a marketing team of five individuals. This team put on street plays, played games with children and others in the village, and gave away prizes. These shows and activities highlighted the symptoms of anemia, the body's need for iron, and the benefits of consuming Tata Salt Plus. The shows happened in the most central location of each village or section of the village to maximize attendance. These information campaigns took place in all Sales villages within a few days of initial stocking, with each village receiving between one and three shows or activities depending on the size of the village.

For our second test, we randomly selected 62 Sales villages to be the locations of the free DFS experiment. In those Sales villages, we randomly assigned 7 out of the 15 measurement households to receive free DFS delivered to their homes. Another dedicated team delivered two kilograms of salt at home every two and a half to three months for nearly two years to 438 households. This amount was set using salt consumption figures for Bihar, which average $8 \mathrm{~g}$ salt per person per day. Households not receiving DFS for free may have known that a few households in their villages were receiving it for free at home.

In addition, we performed a number of additional marketing experiments in Sales villages, which are described in detail in Banerjee et al. (2016) ${ }^{6}$

\section{Data Collection}

We conducted surveys in all 400 villages using teams of surveyors who were trained by a medical doctor to take a drop of blood and measure hemoglobin using the HemoCue method:7 The team also directly measured physical health including weight, height, mid-upper arm circumference, and aerobic capacity and balance (Queens Step Test).

We used an in-depth survey to assess a range of additional household-level and individuallevel outcomes. At the household level, data was collected on household composition, income,

$6 \quad$ The additional cross-randomized marketing experiment treatments comprised an edutainment film shown in villages, a flyer delivered to households, and a one-time discount to a set of chosen retailers.

7 This testing method has been found to be comparable to standard laboratory techniques for measuring hemoglobin in normal and anemic children (Cohen and Seidl-Friedman, 1988) and to adequately estimate population anemia (Neufeld et al., 2002). 
assets, consumption, nutritional intakes, socio-economic characteristics, household health service usage, and DFS adoption. 8

In order to measure impact on productivity and economic outcomes, we collected individuallevel data on level of education, hours worked, earnings, allocation of time to voluntary and leisure activities and, for children, school attendance. Additionally, we collected information on self-reported health and mental health status, including ability to perform various Activities of Daily Living, as well as symptoms and diagnoses of illness (cold, pain, diarrhea; blood loss, malaria, etc). Women aged 15 years and over were also asked about the outcome of pregnancies within the intervention period.

Finally, developmental and cognitive outcomes were captured through four standardized measures. Our Infant Development Module was based on the Lucknow Development Screen, which captures developmental delays among infants between the ages of 1 to 30 months and has been validated for use among children in India (Bhave et al. 2010). Mothers or another close family member are requested to report on the childs ability to perform a certain age-appropriate task. The task is considered age-appropriate if $97 \%$ of infants at that age are able to perform the task.

Child and adult cognition were measured using sections from the National Institute of Mental Health and Neuro Sciences (NIMHANS) neuropsychological battery and the Post Graduate Institute of Medical Education and Research (PGIMER) battery of memory dysfunction, which were previously validated in India 9 The Child Cognition Module uses the Digit Span test from the PGI battery and the Visuospatial Working Memory Span Test from NIMHANS, which measures memory and retention. The Adult Cognition Module consists of four sub-tests from the PGI battery, including the Digit Span Test, Word Recall Test, Sentence Recall Test, and Word Pairs Test. Scores from the sub-tests are aggregated to measure memory and retention.

Among the elderly, we used the Hindi Mental State Exam, designed to measure basic cognitive awareness and alertness among a lower-income, Indian population. The Hindi Mental

$8 \quad$ Given our focus on nutrition, a household in this project is defined as a group of people living together under the same roof and eating from the same pot for six out of the past twelve months.

9 The NIMHANS battery is composed of tests taken from other standardized test batteries, such as the LuriaNebraska Neuropsychological battery. The PGIMER battery of memory dysfunction is comprised of 10 subtests including forward and backward digit spans, one minute delayed recall of a word list, immediate recall of sentences, retention of similar word pairs, retention of dissimilar pairs, visual retention, visual recognition, recent memory, remote memory and mental balance test. 
State Exam (Ganguli et al., 1995) was developed by researchers from the University of Pittsburgh and the Centre for Ageing Research, India. 10

Across all the surveys, eligibility to participate in a particular survey was determined by age. Table 1 describes the age requirements for the outcome measures. The age cutoffs were defined as shown in order to match the National Family Health Survey (NFHS), which defines elderly as 50 years or older and adults as between 15 and 49 years of age (International Institute for Population Sciences (IIPS) and Macro International, 2008).

\subsection{Empirical specifications}

First, we analyze the sales experiment by comparing households and individuals in Sales villages to those in control villages.

In our basic specification, for any outcome $y_{i k}$ for individual $i$ in village $k$, we run the following regressions:

$$
y_{i k}=\alpha+\beta \text { Sales }_{k}+X_{i k} \gamma+\delta B a s e H b_{i k}+\epsilon_{i k}
$$

where Sales $_{k}$ is a dummy equal to 1 if DFS was made available in village shops, $B a s e H b_{i k}$ is hemoglobin concentration at baseline and $X_{i k}$ is a vector of control variables (age, age squared, a dummy which indicates if the individual is anemic at baseline, a dummy for household split, education above 5th grade, BMI at baseline -all set to zero if we don't observe the individual at baseline, household wealth index, a dummy for whether we have baseline measurements, and a dummy for each block as the randomization was stratified by block). The inclusion of control variables makes very little difference. The standard errors are clustered by village, the unit of randomization for the sales experiment.

We also use this specification to look at pre-defined subgroups (male, female, children, adults, and elderly) because of different biological requirements for iron by sex and age. Specifically, we adjust for the two male/female subgroups and three subgroups by age children/adult/elderly. When we do this, we provide both conventional standard errors, and q-value

10 The research team adapted a battery of tests that were developed to diagnose dementia in an educated English-speaking population to be used in Northern India with Hindi speakers who have little or no formal education and were largely illiterate. The test includes sections on orientation to time, orientation to place, registering and recalling basic objects, attention by subtracting serials threes, naming everyday objects, repetition of a phrase, following a visual command, executing a three-step task, saying something about one's houses, and copying a simplified figure. 
which adjusts for multiple testing using the false discovery rate (Anderson, 2008).

We also run this specification separately for anemic individuals, since, consistent with medical evidence, the literature before us finds effects of iron supplementation on hemoglobin concentration and anemia only for those who were anemic at baseline.

When we look at possible "downstream" impacts (on cognition and physical and mental health), we adjust for the fact that we are looking at multiple outcomes in two ways: first, we aggregate all the measures for each of these impact cognition in order to make separate cognition, physical fitness, and mental health indices; second, we provide q-values to account for the fact that 3 outcomes are tested (in addition to testing the different subgroups).

In turn, we analyze the free DFS experiment in two ways. First, we compare individuals in households who received free DFS with those from households in control villages to focus on the highest expected consumption compared to no introduction of the product at all. We start with the following specification and exclude all households in Sales villages who did not receive the free DFS.

$$
y_{i k}=\alpha+\beta \text { freeDF } S_{k}+X_{i k} \gamma+\delta B a s e H b_{i k}+\epsilon_{i k}
$$

Standard errors are still clustered at the village level, and we conduct the same subgroup analysis (and related adjustment for multiple hypothesis testing).

Second, we exploit the within-village randomization by restricting the to 930 households in the 62 villages where the free DFS household-level randomization took place and comparing those who were and were not provided free DFS. This sample restriction still results in a randomized sample, since households that received the free salt were randomly selected within a set of villages. This specification allows us to identify the impact of free versus discounted iron fortification, controlling for village-level information campaigns. The basic specification is analogous to the basic sales experiment specification, but adds a dummy for each village since the randomization was stratified by village.

$$
y_{i k}=\alpha_{F}+\beta_{F} \text { FreeDF } S_{i k}+X_{i k} \gamma_{F}+\delta_{F} \text { BaseHb } b_{i k}+\mu_{k}+v_{i k}
$$

Where $\mu_{k}$ is treated as a set of fixed effects. In this case the standard errors are not clustered at the village level, but instead are clustered at the household level. 
Equations 2 and 3 are both estimated for the entire sample, males and females separately, and then by age groups, across multiple outcomes. We also estimate these specifications for the same subgroups restricted to those individuals who were anemic at baseline.

Finally, we take an instrumental variables approach, combining two sources of variation; the dichotomous "free DFS household" and "Sales village" treatment variables are used as instruments for recent salt consumption, as indicated by either the household currently consuming DFS or the household reporting that they used DFS right before their current salt (penultimately used DFS). The first stage is simply:

$$
U s e D F S_{i k}=\pi_{0}+\pi_{1} \text { FreeDF }_{i k}+\pi_{2} \text { Sales }_{k}+X_{i k} \pi_{3}+\pi_{4} \text { BaseHb }_{i k}+v_{i k}
$$

where $U s e D F S_{i j}$ is a dummy equal to 1 if household $i$ of village $k$ is currently using DFS or was using it last time ${ }^{11}$ We then estimate the equation:

$$
y_{i k}=\alpha_{U}+\beta_{U} U s e D F S_{i k}+X_{i k} \gamma_{U}+\delta_{U}{\text { Base } H b_{i k}+v_{i k}}
$$

by two stage least squares, using FreeDF $S_{i k}$ and Sales $_{i k}$ as instruments for UseDF $S_{i k}$ and the other variables as instruments for themselves.

\subsection{Balance}

Table 2 presents summary statistics for both experiments in Panel A (individual level variables) and Panel B (household-level variables). It demonstrates that the Sales arms were very balanced, with none of the characteristics showing significant differences between treatment and the control groups (Column 3). The free DFS sample is quite large, and randomized at the household level within strata. There are a few significant differences between households who received and did not receive free DFS (Column 7), but the point estimate of the differences are very small. Most notably, hemoglobin concentration was a little lower at baseline in the free DFS group (12.07 $\mathrm{g} / \mathrm{dL}$ versus $12.178 \mathrm{~g} / \mathrm{dL}$ ), but they were actually a little less likely to be anemic (16\% vs $18 \%$ ). Education is a bit lower in free DFS households (fewer heads of the household finished 5th standard), and more households split between baseline and endline ${ }^{12}$ We do control for all

\footnotetext{
11 This will provide smaller and more precise estimate than if we used "currently using DFS" but since there could be lingering effect of having used DFS, it seems to be the best intermediate variable to use.

12 If a household split, we include both resulting households and their members in the endline.
} 
these variables in our regressions.

\subsection{Attrition}

Table 2, Panel C looks at household and individual level attrition for both experiments. Attrition would be a threat to the validity of our estimates if it changes the unobserved characteristics of one treatment group relative to another. For example, if repeat contact with a stranger when receiving free salt made free DFS households take more trouble to help schedule a follow-up visit for our surveyor to interview all members at endline, we may have found more of the mobile types belonging to households receiving free DFS compared to others. If mobile persons (migrants) have lower (higher) hemoglobin than others, we could under (over)-estimate the impact of free DFS.

We did not lose many entire households over the 2.5 years between baseline and endline, with the fewest percentage-wise lost from the free DFS treatment group. Household attrition was roughly $4 \%$ in the control villages, $5 \%$ in Sales villages, $4 \%$ among households not receiving free DFS in the free DFS villages, but only $2 \%$ for households receiving free DFS (Row 1). These figures are slightly imbalanced across both experiments. At the individual level, attrition is balanced for the sales experiment (though much higher at roughly 19\%). For the free DFS experiment, attrition is again lower among individuals in households receiving free DFS (15\%) compared to the control group (18.5\%) within free DFS villages (Panel C, Column 7).

At the same time, a number of individuals were also added to the sample between the baseline and the endline (for example, only $81.9 \%$ of the control sales sample was present at the baseline, and this is balanced across group). Some of these individuals are genuinely new to the household, for example because of marriage, or birth. Furthermore, some individuals were missed at baseline. ${ }^{13}$ And finally, we suspect that attrition is actually much lower than what we think, because some of the "added" individuals might actually be "attrited" individuals who are mismatched. For this reason, and because we see very little chance of endogenous joining of households due to the treatment, we keep all the individuals in the analysis sample, although not including them does not affect the estimates very much.

Appendix Table 12 shows a comparison of baseline characteristics of non-attritors by group to check for balance in the endline sample. Columns 1-3 demonstrate that both indi-

13 No households was added, unless they were a split from a baseline household 
vidual (Panel A) and household-level characteristics (Panel B) are balanced across control and Sales villages. Columns 5-7 demonstrate that balance is still a bit of a concern comparing free DFS households with non-free households in free DFS villages. However, it is the same - or marginally less of a - problem than in the full baseline sample. Baseline hemoglobin concentration is balanced across Free and non-Free households in the sample of non-attritors, while it was slightly imbalanced in the full sample measured at baseline. Therefore, attrition has not worsened balance on observables across treatment and control conditions. Nonetheless, we control for baseline characteristics in our basic specification, including hemoglobin, education, etc. The Online Appendix reproduces our analysis excluding the "new" individuals, and results are substantively the same.

\section{Results}

Making double fortified salt available through shops did result in fortified salt consumption. Panel D in Table 2 shows descriptive statistics on the take up of double fortified salt, averaging over all subgroups. On average, approximately two years after DFS was launched in local shops, $14.5 \%$ of households in sales villages are consuming the product. $21.8 \%$ are consuming it at the time of the survey or the previous time they bought salt. $42.6 \%$ of them have ever tried it. This level of take up is somewhat lower than what the results we had our initial pricing experiment, where we saw take up of about $30 \%$ at a price of ₹9 (Banerjee et al. 2011), despite the fact that we had much more intensive interventions to encourage take up in many of these villages (Banerjee et al., 2016). However, this take up is actually larger than what our partner, TCL, told us to expect when launching a new product. From this point of view, it seems that the DFS launch, and the accompanying interventions, were actually as large a success for a social marketing experiment as what one could hope to see. In Banerjee et al. (2016), we discuss the impact of various methods to encourage take up: take up was 5 percentage points higher in villages where a very entertaining edutainment movie on DFS was shown and 5 percentage points higher in villages where all shopkeepers were given an incentive to sell the salt. What is a bit worrisome is that the take up does appear to fall over time: many people tried it at least once but did not continue with the product. Figure 3 shows that at the store level, purchases also fell over time. This suggests that the product does not have a slow diffusion curve that would eventually culminate in large adoption. Instead it seems that many people tried it but 
gave it up after a while. There were some early reports of food turning black as a result of adding the salt. We tracked this consistently with free DFS households and this seems to occur very infrequently if ever, but this is clearly something that was of concern to some number of households at first.

\subsection{Main results on Anemia and Hemoglobin: Sales Experiment}

Table 3 shows the results of estimating equation (1) for the entire sample (column 1) and women and men separately. The bottom line is relatively clear for the full sample.

Overall, there is a small increase on average hemoglobin concentration $(0.045 \mathrm{~g} / \mathrm{dL}$, significant at the $10 \%$ level $(95 \%$ CI $-0.009 ;+0.099)$, and a small and insignificant decline on anemia rate (-0.9 percentage point, $95 \%$ CI -1.7 percentage point; +1.4 percentage point). The results are small, but also, owing to the large sample size, quite precise, and the confidence intervals are tight. We can reject even a small decrease in anemia prevalence.

For women, there seems to be no significant effect of being in a sales village on anemia, and small and insignificant positive effect on hemoglobin concentration. The $95 \%$ CI for anemia is $(-2.2$ percentage points; +1.8 percentage point). Thus, we cannot reject that the impact of being in a sales villages had no effect, and we can reject that it had even a small effect (there were $59.7 \%$ of women anemic at baseline). For men, there is a reduction in anemia rate of 1.6 percentage point, although it is not significant with adjusted q-values, and an increase in hemoglobin concentration of $0.06 \mathrm{~g} / \mathrm{dL}$. But there again, we can reject even moderately sized impacts: for example, the $95 \%$ confidence interval is $(-3.5$ percentage points; +0.1 percentage points) for the fraction of men who are anemic (37.5 percent of men are anemic at baseline).

The effects are larger for individuals who were anemic at baseline. For women, the estimates suggest a slightly larger effect for those who were anemic at baseline, but the effect is still insignificant for them. For men, however, the effects are significantly larger for those who were initially anemic at baseline, and the significance is robust to adjusting the p. The point estimate suggest a 3.5 percentage point reduction in the proportion of anemic individuals ( $q$ value $=0.048$ ), and an increase of $0.145 \mathrm{~g} / \mathrm{dL}$ in $\mathrm{Hb}$ concentration (q value $=0.018)$. Even there, however, we can reject a large effect. With a $95 \%$ confidence interval for $\mathrm{Hb}(+0.037 ;+0.25)$ we can reject a increase of $2 \%$ or higher in $\mathrm{Hb}$ concentration for males who were anemic at baseline, the group that seems to benefit the most. 
In sum, despite a reasonable (if not stellar) take up of the DFS when sold at half the regular market price through regular shops and PDS shops, the impacts on hemoglobin concentration and anemia were at best very limited, and concentrated on anemic males.

Our social marketing experiments (reported in detail in Banerjee et al. (2016)) induced greater take up in some villages than in some others. In particular, DFS take up (measured as "currrently using DFS") was about 5 percentage points higher in villages where we showed a high production value "edutainment" movie, and in villages where shopkeepers were given an incentive to market DFS. Using our preferred specification (controlling for baseline hemoglobin level), we examine whether this increased take up was sufficient to generate larger impact on hemoglobin concentration or anemia by endline. We find no difference in any of these villages (Appendix Table 11).

\subsection{Main results on Anemia and Hemoglobin: Free DFS experiment}

The limited impact of the sales experiment could be the product of two things: modest take up (though probably as high as could be obtained with this kind of product) and the impact of the product. Our power calculations, based on the results of the small take up experiment, assumed a somewhat larger take up of about 30\%. Although almost half the sample ever tried the product, the final take up ended up being a bit lower than that.

As mentioned, the level of fortification of DFS is not very high: if only using DFS and consuming $10 \mathrm{~g}$ of salt per day, an individual would only get $10 \mathrm{mg}$ of iron per day, or about $30 \%$ of their RDA of iron from DFS, much less than what is provided by iron supplements Banerjee et al. 2013). This is about half the quantity that was provided in the WISE study (Thomas et al. 2006$)$, although more similar to the overall dose received by adolescents in Peru (Chong et al., 2015). The hope was that regular DFS availability by households would be sufficient to complement other sources of iron in an individual's diet, or that the increase in iron, even if still insufficient, would be enough to make a difference. Surprisingly, as we noted, there is no empirical evidence backing that claim. To test this hypothesis, we distributed free DFS to households, with the aim of increasing the take up of the program. There was, however, no obligation for them to use it. Our free DFS experiment is the first large-scale efficacy trial of free DFS fortification to our knowledge.

Table 2 shows that the take up of free DFS was high when distributed for free. Not all 
households tried it (only about $75 \%$ of the households ever tried DFS for consumption) 14 , but many did. Furthermore, those who did were using it until just before the endline, and some of them had stopped because their supply had just run out. $75 \%$ of them where using it currently or last time they used a packet of salt (they had recently run out). $61 \%$ were using it currently (which means that they did not buy DFS if the free amount ran out). This suggests a reasonably good acceptability of the product. Thus, if the impacts were large, free distribution of double fortified salt to poor households would in fact be a feasible strategy. Meanwhile, the take up for households in free DFS villages who did not get it for free was $15.6 \%$, and thus this creates a large difference in take up.

Tables 4 and 5 show reduced form impacts of being in the free DFS sample on anemia and hemoglobin concentration, either compared to the control group, as in equation (2) or compared to other households in the same villages as in equation (3).

In Table 4, the effect is very similar for the whole sample to the results of the Sales experiment (point estimate of $0.044 \mathrm{~g} / \mathrm{dL}$, with larger standard errors). The pattern by subgroups is a bit surprising however: the effect is not larger in the anemic subsample, and, in contrast to the Sales experiment, the effects are now smaller for men than for women. With a smaller treated group (6253 individuals), the standard errors are also larger, which may diminish our ability to find statistically significant results. Comparing the households who received free DFS to those in free DFS villages who did not receive the product, we find even smaller point estimates. For example, for the whole sample, the point estimate on Hb concentration -0.009 (95\% CI: -0.097; $+0.079)$.

\subsection{Impact of Sales and Free DFS on Anemia and Hemoglobin: Subsamples}

This project was in part funded by the NIA, and our original proposal called for examining impacts separately for children, prime age adults, and older adults (Banerjee et al., 2010).

Tables 3-5also present results on hemoglobin concentration and anemia at endline for these subgroups 15 In the sales experiment, impacts are the strongest for children: there is an increase in $\mathrm{Hb}$ concentration of 0.068 , significant at the 5 percent level, weaker for prime-age adults (not significant), and wrongly signed for elderly (though insignificantly so). All the results

14 Anecdotally, we know that some households gave it away or gave it to animals

15 To limit the number of subgroups, we pool the age group by gender, the further disaggregated results are available up on request. 
are stronger when focusing on individuals who were anemic at baseline, but still significant only for children (0.134 increase in Hb concentration in this group).

In the free DFS experiment (Table 4) the ranking is the same when comparing to control, and we still find effects for children $(0.097 \mathrm{~g} / \mathrm{dL}$, significant at the $10 \%$ level). Surprisingly, we find a negative point estimates on $\mathrm{Hb}$ concentration among the elderly, which is significant at the $10 \%$ level. This may be a chance result, since we are testing different subgroups, but is nevertheless surprising. The negative impact is even larger when focusing on those who were anemic at baseline. We find the same result when we testing subgroups by comparing the free DFS households to other households in the same village (Table 5), though not significant, suggesting that, even this if this is a chance results, this is driven by something that happens specifically in the free DFS households.

\subsection{Instrumental Variable Estimates}

The two experiments can be combined to provide an instrumental variable estimate of the actual consumption of salt. There are several candidate variables to measure the exposure to DFS: currently using DFS; used it currently or last time; or ever used it. All this does is scale the estimates by a different factor. We chose "using DFS now or having penultimately used DFS" because if households last packet was DFS, they were recently exposed, and we should still see impacts.

Table 6 shows a very robust first stage for actual DFS adoption: households in Sales villages are 16 percentage points more likely to consume free DFS. In addition, households who got the free DFS treatment are an extra 49 percentage points more likely to consume free DFS. Interestingly, individuals who were anemic at baseline (who may be expected to benefit more) are no more likely to consume DFS, most likely because they are not aware of their status.

Table 7 present the results of the 2SLS estimation for all our outcomes. The presentation of the table is slightly different from previous tables. Columns (1) to (6) show the effect for all, females, males, all anemic, female anemic, and male anemic. Not surprisingly, given the reduced form estimates discussed earlier, none of the estimate are significant, and while some are positive, some are even negative. For women, the impact is a -0.007 percentage point reduction in the fraction anemic (95\% CI: $-0.073 ;+0.059)$ and a 0.043 increase in $\mathrm{Hb}$ (95\% CI: $-0.15 ;+0.23)$. So we can reject a 2 percent increase in $\mathrm{Hb}$ level. For anemic women, the $95 \% \mathrm{CI}$ for $\mathrm{Hb}$ 
concentration is $(-0.148,+0.39)$, so we can still reject a 3.5 percent increase. For men, the point estimates are both negative (this is because of the negative impact of free DFS, which more than compensates for the positive effect in the sales sample). For anemic men, the confidence interval for $\mathrm{Hb}$ concentration is $(-0.43 ; 0.21)$. We discuss how these point estimates compare with others in the literature in Section 4.1.

We also estimate the impact of our treatments on adolescents separately as other studies have found an impact of free DFS distribution on schoolchildren (Sivakumar et al. 2001) or of iron supplementation on adolescents (Chong et al., 2015). Table 10 presents all comparisons and models: Panel A shows the sales experiment, Panel B shows the free DFS OLS results comparing with the control group, Panel C shows the free DFS OLS results comparing to non-free households, and Panel D presents the second stage IV results. We look first at hemoglobin for all adolescents and then adolescents who were anemic at baseline, followed by fraction anemic, again for all adolescents and then adolescents who were anemic at baseline. All of the OLS results are correctly signed, but small and not statistically significant (Panels A - C). However, the second stage of the IV strategy reveals an increase of $0.410 \mathrm{~g} / \mathrm{dL}$ for all adolescents with a corresponding decrease in anemia of 12 percentage points (Panel D Columns 1 and 3). These results, however, are not driven by the adolescents who were anemic at baseline (Panel D, Columns 2 and 4), suggesting DFS may have protected the non-anemic from declines in hemoglobin.

\subsection{Impacts of Sales and Free DFS on Cognition, Physical and Mental Health}

Tables $8 \mathrm{a}, 8 \mathrm{~b}$ and $8 \mathrm{c}$ describe results for cognition, physical health, and mental health. For these tables, we summarize the impact using standardized measures that reflect several indices. We present conventional standard errors as well as standard errors that adjust for multiple hypothesis testing both for multiple variables (we have 3 indices we test together) and, as before, for each outcomes, for our six subgroups. Thus, for example, any q value in the "male" column adjusts for 6 hypotheses tested together, and any q value in any of the 3 age groups adjust for 9 outcomes tested together.

The cognition, mental health, and physical fitness indices were constructed using the baseline mean and standard deviation from the sales experiment control group for the given variable of interest. A cognition module was performed on all respondents over the age of 1 month, with one of four module types being given dependent on age, as shown in Table 1 . The 
scores from each of these were modules were standardized by the baseline mean and standard deviation from the sales experiment control group for that given module. The cognition scores are standardized such that a positive score indicates a higher level of cognition.

For our mental health index, only respondents 10 years or older were eligible for these questions. The set of questions we used to construct this index are modeled after the CES-D depression index (Radloff, 1977). Children (ages 10-15) and adults (15+) were asked slightly different questions; therefore, the scores were first summed and then standardized separately. Since a higher score indicates a greater level of depression, we multiplied the original standardized variable by negative one so that a positive value could be interpreted as having better mental health.

Lastly, for the physical fitness outcomes, only respondents over the age of 10 who were not pregnant and could stand alone unassisted were eligible for the physical fitness module. Depending on age and whether the respondent had any arthritis or knee conditions, one of two batteries of tests were completed. Each of the individual tests were first standardized, and then the battery of tests was standardized in order to obtain the standardized physical fitness score. Again, we multiplied the original standardized variable by negative one so that a positive value could be interpreted as being more physically fit.

Not surprisingly, given that there is no impact on anemia, we also find little impact on any of these measures, neither for the sample as a whole, nor for any particular subsample. Neither physical health, nor mental health, nor cognition, seems to have improved in any group. The standardized physical fitness scores increase by 0.02 standard deviation overall in the sales experiment (95\% CI: -0.048;-0.088, see Table 8b), so we can reject even a fairly small effect at the $95 \%$ level. The mental health scores increase by 0.005 in the sales experiment (95\% CI: $-0.035 ;+0.045)$, allowing us to reject an even smaller impact. The 2SLS impact of consuming free DFS is a bit noisier point estimate, and we cannot rule out moderately sized impact on physical health (95\% CI: $-0.09 ; 0.24)$ and mental health (95\% CI $-0.17,0.145)$, but we can still rule out large effects.

One potentially important exception to a general pattern of lack of effect is the cognition scores (Table 8a), which actually show a decline in the overall sample in the free DFS experiment, although the decline is not significant 16 Inspecting the subgroups, it is clear that the decline

$\overline{16}$ It is for men with conventional standard errors, but not with adjusted q value. 
is driven by the elderly group, where we had seen the largest (although insignificant) declines in hemoglobin concentration. For the elderly group, in particular for those who were anemic at baseline, we find sizable and significant decline in cognition score. The point estimate for the anemic group is -0.229 standard deviations, with an adjusted q value of 0.03 . The medical literature establishes a clear link between anemia and cognitive function, including dementia (Andro et al., 2013). Our cognitive test for the elderly is designed to pick up age-related decline. Conversely, Chong et al. (2015) find large gains in cognition for adolescents whose hemoglobin levels did improve. Thus, this robust effect suggests that the insignificant but large decline in hemoglobin concentration (which is perhaps less precisely measured) might in fact be real.

\section{Discussion}

\subsection{Comparison with Decentralized Iron Fortification of Flour}

For two of the authors of this paper, this was not the first (failed) attempt at fortifying food with iron for the poor.

From 2006 to 2009, we set up and evaluated a community-level iron fortification program in 134 villages (65 villages were chosen as treatment villages) in Udaipur district, Rajasthan (Banerjee et al. 2011). In this area, households get their grain (maize or wheat) milled once or twice a month by a local miller, or chakki. The community level iron program was designed to increase bio-availability of iron for families who do not buy commercial food, and was designed and implemented by Seva Mandir, a well-respected local NGO.

On average, each hamlet has 4 chakkis (this is also the median number). In each village, Seva Mandir chose the two chakkis, serving the majority of the households. A fortification program must meet two objectives: supply a sufficient quantity of iron in the diet, and avoid supplying too much iron. Safety is also a concern, as the process will not be as tightly monitored as it can be in a factory. It is important that the program is robust to accidental over fortification. The technology for fortification begins with a pre-mix, a dry powdered mix with specific concentrations of one or more micronutrients. This pre-mix is diluted into a pre-blend (because pre-mix is too concentrated to be properly hand-mixed into the flour) and then added to flour either (1) during the milling process or (2) after the grain has been milled.

After consultations with micronutrient initiatives and various experts, Seva Mandir chose 
to use ferrous sulfate (FeSO4) and folic acid (which helps with iron absorption). This pre-mix was then mixed with flour at Seva Mandir (16.66 gs of pre-mix is added in one $\mathrm{kg}$ of flour), to produce a pre-blend which had 3300 ppm (or milligram per $\mathrm{kg}$ ) of elemental iron (as ferrous sulfate). This quantity is sufficiently diluted so that if someone were to eat the pre-blend without mixing, there would be no health risk. This pre-blend was then mixed with the ground grain (maize or wheat) in the appropriate quantity, using a measuring scoop, and a simple mixing machine. The customer were not charged for the fortification.

The final concentration of iron in the flour thus ranges from about 20 to $33 \mathrm{mg}$ per $\mathrm{kg}{ }^{17}$ A pilot survey on the kilograms of flour milled showed that the average adult eats .3 kilograms of flour per day. This implies that the average adult would get an extra 6 to $12 \mathrm{mg}$ of iron from the fortified flour, spanning the $10 \mathrm{mg}$ of iron that would have been provided by the consumption of $10 \mathrm{~g}$ of DFS.

Before the program was started in a village, a village meeting took place, in which the cause and consequences of iron deficiency anemia were discussed, as well as what households could do to prevent it (changes in diet). The program was then explained to the village, and the village collectively agreed to participate (all villages agreed) 18 At the individual level, a household had to initially agree to be a participant. Once a household accepted the program, the chakkis were to consider them to be participating households, unless they explicitly declined fortification.

However, in spite of the initial decision to fortify, many households did not regularly fortify, either because the chakki did not always fortify the grain, or because households switched to non-participating chakkis. Figure 2 plots the take up of the program as a function of the date the program started

and separates the households in 3 groups: those for whom the closest chakki fortifies; those who do not fortify, but have a fortifying chakki nearby (within 1.5 kilometers); and those who do not have a fortifying chakki within 1.5 kilometers. Take up initially increases in all three groups, but does not reach the same peak for those who do not have a chakki nearby. All those who have a chakki nearby reach the same peak, but take up falls down more quickly for those for

$17 \quad$ Except for the top of the first bin.

18 To avoid creating spurious effects due to the information regarding anemia, Seva Mandir held a village meeting in control villages as well, where the discussion was the same (except that the program was not discussed). 
whom the participating chakki is not the closest one, presumably because households switched back to their normal chakki after a while.

By the time of the endline survey there was, as in the DFS experiments, no impact on anemia or hemoglobin (see Table 9, which reproduces Table 4 from Banerjee et al. (2011)). In the IV specification, the standard errors are a bit larger than in the DFS study, but the confidence intervals in both studies have large zones of overlap.

These interventions tried to attack the fortification problem in two ways: by offering households a technology to fortify their own flour or by making double fortified salt available at a price below that of regular iodized salt. Both would have provided nearly the same amount of iron if consistently taken up. Both foundered on the same problem: take up declined over time, and level of fortification was probably too low to lead to significant improvement for most people.

\subsection{Comparison between Sales Experiment and Free DFS Experiment}

Contrary to our expectations, we do not find the free DFS intervention to be more effective than the simple Sales intervention. The point estimates in the entire sample are comparable, and if anything, the sales intervention seems to have helped the anemic people (especially anemic males) more than distributing DFS for free. This is despite the fact that consumption is much higher among those who get free DFS. This may of course be due to chance: the confidence intervals do not really allow us to rule out that in fact the sale of DFS was more effective. But there are some alternative explanations.

First, the sales intervention was accompanied by social marketing, emphasizing the importance of iron and it is possible that this played a role through diet change. To investigate the role of social marketing, we screened an edutainment movie about DFS in some control villages as well. We do not find any effect of this intervention on anemia or $\mathrm{Hb}$ (Appendix Table 11).

Second, those individuals who would benefit from the treatment most may have been buying it in the sales villages anyway, so that the marginal person receiving free DFS in the free DFS treatment has a lower impact. One suggestion that this explanation may not be the case is that anemic individuals are no more likely to consume DFS than non-anemic individuals, and we do know there is a larger impact in the sales treatment for the anemic at baseline subgroup.

Third, the consumption of free DFS may have been much less systematic in the free DFS 
group than for households who bought it, since it was given to households for free and they did not feel they had invested in it. However, there is growing evidence of this "sunk cost" fallacy effect in the literature (see Dizon-Ross et al. (2015) for a recent summary).

Fourth, households may have been overestimating the good that DFS would do them, and overcompensated by doing less of what they would otherwise do to prevent anemia.

\subsection{Comparison with Two Iron Supplementation Interventions}

This section compares our results to the WISE experiment in Indonesia (Thomas et al., 2006) and the encouragement design for the take up of iron supplements in Peru (Chong et al., 2015).

In Thomas et al. (2006), the treatment individuals received $120 \mathrm{mg}$ per week, and compliance was excellent, due to very active follow up. This was not envisioned as a potential policy, but as a "mechanism experiment" with rich data to investigate the impact of improving iron intake. With perfect compliance, and if each individual consumed $10 \mathrm{~g}$ of salt per day, our experiment would only have led to an increase of iron intake of $70 \mathrm{mg}$ per week, or about $60 \%$ what was given in Thomas et al. (2006).

Thomas et al. (2006) only find results among those who were anemic at baseline. For anemic males, they find an increase in $\mathrm{Hb}$ of $0.4 \mathrm{mg} / \mathrm{dL}$. Our corresponding point estimate for the IV specification for anemic males is negative, but with a confidence interval of $(-0.43 ; 0.21)$. We can thus reject their point estimate, but since we only fortified at about half the level of what subjects received in Thomas et al. (2006) (assuming that those who consumed DFS did so regularly) the order of magnitude is reasonable. This would suggest that the level of fortification of the DFS is simply insufficient. For anemic females they find $0.203 \mathrm{mg} / \mathrm{dL}$ in increase in Hb. Our $95 \%$ confidence interval for the IV estimate is $(-0.15 ;+0.23)$. In this case, we cannot reject their point estimate.

In Chong et al. (2015) the treatment group (which was encouraged to take up the pill) received on average five more pills than the control group, which is $500 \mathrm{mg}$ over three months (the control group also received about $500 \mathrm{mg}$ over three months, so on average the treatment group received $1000 \mathrm{mg}$ over three months). This is only a third of what individuals received in Thomas et al. (2006) and about $55 \%$ of what someone who would ate enough DFS regularly would obtain. Despite this lower dose, they report very high estimates for a sample of adolescents, ages 13-17. For boys and girls together who were anemic at baseline, the effect on $\mathrm{Hb}$ is $0.5 \mathrm{mg} / \mathrm{dL}$. They 
don't report a standard error for this difference, but they also find a decrease of 21 percentage points in anemia among the initially anemic adolescent, with a $95 \%$ confidence interval of $(-0.42$; +0 ). This is much larger than the reduction in anemia found by Thomas et al. (2006) (about 3 to 4 percentage points, insignificant), and of course much larger than what we find for the sample as a whole.

The contrast between the Chong et al. (2015) and the Thomas et al. (2006) suggests that the impact of supplementation may be much larger for adolescents than for adults. To investigate this possibility, we run our main OLS and 2SLS estimates in the sample of adolescents. The results, presented in Table 10 are indeed more encouraging in this sample. We find a positive (but insignificant) impact of the sales experiment, but a stronger positive effect of the free DFS experiment. Compared to the entire sample, adolescents in the free DFS experiments where 5.9 percentage point less likely to be anemic by endline. Looking a the IV estimate hemoglobin is $0.41 \mathrm{~g} / \mathrm{dL}$ higher with a $95 \% \mathrm{CI}$ of $(+0.038 ;+0.782)$ and anemia is 12.1 percentage points lower (95\% CI: -0.219; -0.023). This ranges include the Chong et al. (2015) result for anemic children, both for anemia and for $\mathrm{Hb}$ concentration. 19 We also investigated whether we have impacts on the health, mental health and cognitive outcomes for this sample of adolescents, but do not find anything, contrary to Chong et al. (2015) .

To summarize, the comparison with two very well implemented field RCT of fortification suggests that our estimate are consistent with the literature, given how fortification could be brought via salt. But it seems that those effects are just too weak for the population at large. The adolescent results, however, gives some indication that supplementation targeting specifically adolescents (though pills or through food fortification in school meals) is a promising avenue.

\subsection{Comparison with other DFS evaluations}

There have been several field trials - seven to our knowledge - with other formulations of ironfortified, iodized salt in four low or middle-income countries, in addition to the two experiments with NIN's DFS in India 20

19 One difference is that we find the results when we have all adolescents together, not just who were anemic at baseline. Our baseline, however, was taken two years before, as opposed to 3 months before, and it is possible that the anemia status for adolescent fluctuates enough to be a bit irrelevant as a baseline measure. In their sample, the control group lost $0.78 \mathrm{~g} / \mathrm{dL}$ of hemoglobin over the few months of the study period and the treatment group lost $0.28 \mathrm{~g} / \mathrm{dL}$.

20 There is one additional trial of DFS given for free to the families of 6 to 15-year-olds (Reddy and Nair, 2014). However, the randomization was clustered, with only two schools randomized into DFS or DFS 
Their results are generally positive, increasing hemoglobin by 0.2 to $1.6 \mathrm{~g} / \mathrm{dL}$, though the samples are often small and the length of the trials vary from six months to three years. The most obvious difference between our study and most others is the formulation of iron-fortified salt that was used. Bioavailability of iron in fortified salt is expected to differ along with the level of fortification (and the stabilizer used). At $1 \mathrm{mg}$ iron per gram of salt with sodiumhexametaphosphate as a stabilizer, NIN's DFS contains less iron than some formulas, but the same amount used in three successful experiments in India (Haas et al., 2014, Rajagopalan and Vinodkumar, 2000; Sivakumar et al., 2001) and two successful experiments in other countries (Asibey-Berko et al., 2008; Zimmermann et al., 2003). The salt used in the trial with the largest statistically significant increase in hemoglobin $(+1.6 \mathrm{~g} / \mathrm{dL}$ among children in Morocco, over a relatively short 10 months) was fortified at $2 \mathrm{mg}$ of iron per gram of salt (Zimmermann et al. 2004). However, the trial using salt with the highest level of fortification at $3 \mathrm{mg}$ of iron per gram of salt (in Cote d'Ivoire, over 6 months) did not lead to a statistically significant change in hemoglobin (among children) (Wegmüller et al., 2006).

In addition to formulation variation, often a higher dose than the DFS we tested, there are three features of the existing literature that make it hard to compare results. First, several previous field trials included significant monitoring of usage (Zimmermann et al., 2003, 2004; Wegmüller et al., 2006; Andersson et al., 2008, Asibey-Berko et al., 2008), and consistent and adequate use of free iron-fortified salt may have been higher with intense monitoring than what would be possible at scale. After TCL launched Tata Salt Plus using an interactive information campaign in the sample villages, we did not continually provide further incentives and information to reinforce consumption of the salt, in order to mimic what would be a feasible communication strategy. Instead, we focused on one-time demand-side push interventions, such as the edutainment experiment. Given consumption of DFS was only reported in about $75 \%$

plus deworming medication, and the analysis does not take this clustered design into account. Further, the average child in the study started with a weight of $20 \mathrm{~kg}$, BMI of 13.5 and hemoglobin level of about 8.5 in the DFS plus deworming school and 8.9 in the DFS school. This means the average child was on the low end of the moderately anemic range ( 8 to $10.9 \mathrm{~g} / \mathrm{dL})$. Our baseline sample was much better nourished; the mean girl had a BMI above 15 and hemoglobin level of $11.8 \mathrm{~g} / \mathrm{dL}$ while the mean boy had a BMI of 15.9 and hemoglobin level of 12.2. Another study (Sivakumar et al., 2001) experimented with DFS in India over a 3-year period, and, like us, found no impact on hemoglobin across age groups in a tribal area of Andhra Pradesh. Like us as well, they found an increase in hemoglobin of $1.3 \mathrm{~g} / \mathrm{dL}$ more for males age 14-17 in the DFS group versus the control, but started with a small sample of 22 control individuals and lost nearly two thirds of them by the end of two years. It is therefore unclear if anything can be concluded from these results. 
of free DFS households - a group visited every ten weeks to be given free DFS (a personal reminder) - we would expect that only a very intensive campaign could increase consistency to adequate levels.

Second, the inclusion of deworming drugs alongside fortified salt in four studies (Rajagopalan and Vinodkumar, 2000; Wegmüller et al., 2006; Andersson et al., 2008; Haas et al., 2014) leaves inhibited iron absorption as a potential explanation for the results. ${ }^{21}$ Our intervention was designed for the general population, which would be made much less feasible by the need to provide anti-parasite medication for the entire population (not just students alongside selling fortified salt. Given this design, our data cannot address the question of the possible role of parasites in preventing absorption.

Third, in several "successful" trials, access to other salt or to foods cooked with other salt was limited. Haas et al. (2014) studied female tea pickers in India while Rajagopalan and Vinodkumar (2000) studied male tea pickers, but the subjects' location on remote tea estates meant no other packaged salt was available. There were simply no competing brands or lower quality (less-expensive) salt to use. Sivakumar et al. (2001) reports on experiments with NIN's DFS in India, finding an improvement of $0.7 \mathrm{~g} / \mathrm{dL}$ among schoolchildren over two years. However, the children studied were in residential schools and had access to non-school meals only during school vacation. There were also only four schools randomized into treatment and control and the study suffered from $78.6 \%$ attrition.

\section{Conclusion}

Overall, although these results are only obtained in one setting and probably would need to be replicated, they are not encouraging for the prospect of DFS as a way to fight anemia in rural areas. The previous studies on DFS are very weak and hard to interpret. Our own previous work on decentralized flour fortification had equally disappointing impacts. Overall, the evidence in favor of food fortification as a scalable method to prevent anemia among the very poor is less than overwhelming.

21 Rajagopalan and Vinodkumar (2000) stratified by treatment group and randomized deworming (or not), finding that hemoglobin increased by $0.90 \mathrm{~g} / \mathrm{dL}$ in the dewormed double-fortified salt group and by 0.65 $\mathrm{g} / \mathrm{dL}$ in the dewormed unfortified salt group. Andersson et al. (2008) and Haas et al. (2014) dewormed all subjects, making it impossible to determine if deworming was required for the hemoglobin increases they found. Wegmüller et al. (2006) dewormed all subjects as well, but found no impact of DFS on hemoglobin or anemia. 
This contrasts with positive results of iron supplementation in the two major studies we reviewed. In one study, Thomas et al. (2006), the dose was large and the compliance excellent. This gives us the upper bound of plausible impact of supplementation (which are consistent with what we find), but does not really open a path for a policy. In the other study, Chong et al. (2015), the focus was on adolescents, and adolescents is the one subgroup for which we also find an impact. There, the focus was to improve the take up for a program that was making the pill available, and this seems to be a replicable strategy.

The issue with fortification may be that to make a notable difference for most people (sufficient to perhaps sustain their interest in the product), the iron dose must be large enough. But to be safe (and avoid poisoning due to over-consumption of iron), the concentration of iron supplementation in the food must be limited. With a single source of fortified food, and a diet that continues to be low in iron, the supplementation is perhaps insufficient to make enough of a difference for individuals to be willing to continue with the program. This of course further reduces impact, and ultimately makes the strategy non-viable.

The one exception to this picture may be children and adolescents, who seem to have larger effects both in this sample and in other studies, and may also be made to consume iron, either through fortification of salt or other ingredients through schools. It is worth noting, however, that adolescents can also be reached through targeted pill distributions in school, which is a strategy now pursued by several governments (in India and elsewhere). 


\section{References}

Anderson, M. L. (2008). Multiple inference and gender differences in the effects of early intervention: a reevaluation of the Abecedarian, Perry Preschool, and Early Training projects. Journal of the American Statistical Association 103(484), 1481-1495.

Andersson, M., P. Thankachan, S. Muthayya, R. B. Goud, A. V. Kurpad, R. F. Hurrell, and M. B. Zimmermann (2008). Dual fortification of salt with iodine and iron: a randomized, double-blind, controlled trial of micronized ferric pyrophosphate and encapsulated ferrous fumarate in southern India. The American Journal of Clinical Nutrition 88(5), 1378-1387.

Andro, M., P. Squere, S. Estivin, and A. Gentric (2013). Anaemia and cognitive performances in the elderly: a systematic review. European Journal of Neurology 20(9), 1234-1240.

Asibey-Berko, E., S. Zlotkin, G. Yeung, W. Nti-Nimako, B. Ahunu, S. Kyei-Faried, J. Johnston, M. Tondeur, and V. Mannar (2008). Dual fortification of salt with iron and iodine in women and children in rural Ghana. East African Medical Journal 84(10), 473-480.

Banerjee, A., S. Barnhardt, and E. Duflo (2010). Intervention to Fight Anemia and Improve Well-Being in A Very Low Income Setting. Project 6 of NIH grant proposal funded under P01AG005842-28 (David Wise, PI).

Banerjee, A., S. Barnhardt, and E. Duflo (2013). Nutrition, iron deficiency anemia, and the demand for iron-fortified salt: Evidence from an experiment in rural Bihar. In Discoveries in the Economics of Aging, pp. 343-384. University of Chicago Press.

Banerjee, A., S. Barnhardt, and E. Duflo (2016). Insights in the Economics of Aging, Chapter Movies, margins, and marketing: Encouraging the adoption of iron-fortified salt. University of Chicago Press.

Banerjee, A., E. Duflo, and R. Glennerster (2011). Is decentralized iron fortification a feasible option to fight anemia among the poorest? In Explorations in the Economics of Aging, pp. 317-344. University of Chicago Press.

Bhave, A., R. Bhargava, and R. Kumar (2010). Development and validation of a 
new Lucknow development screen for Indian children aged 6 months to 2 years.

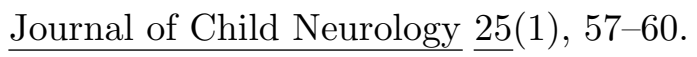

Brahmam, G., K. Nair, A. Laxmaiah, C. Gal Reddy, S. Ranganathan, M. Vishnuvardhana Rao, A. Naidu, K. Vijayaraghavan, B. Sivakumar, K. Krishanaswamy, et al. (2000). Community trials with iron and iodine fortified salt (double fortified salt). In Proceedings of the 8th World Salt Symposium, Volume 2, pp. 955-960. Elsevier Amsterdam.

Chong, A., I. Cohen, E. Field, E. Nakasone, and M. Torero (2015). Iron deficiency and schooling attainment in Peru.

Cohen, A. and J. Seidl-Friedman (1988). Hemocue system for hemoglobin measurement. evaluation in anemic and nonanemic children. American journal of clinical pathology $\underline{90}(3), 302-305$.

de Benoist, B., E. McLean, I. Egli, and M. Cogswell (2008). Worldwide Prevalence of Anaemia 1993-2005: WHO Global Database of Anaemia. Technical report, World Health Organization Geneva.

Dizon-Ross, R., P. Dupas, and J. Robinson (2015). Governance and the effectiveness of public health subsidies. Technical report, National Bureau of Economic Research.

Ganguli, M., G. Ratcliff, V. Chandra, S. Sharma, J. Gilby, R. Pandav, S. Belle, C. Ryan, C. Baker, E. Seaberg, et al. (1995). A Hindi version of the MMSE: The development of a cognitive screening instrument for a largely illiterate rural elderly population in India. International Journal of Geriatric Psychiatry 10(5), 367-377.

Gillespie, S. (1998). Major issues in the control of iron deficiency. Micronutrient Initiative; UNICEF.

Haas, J. D. and T. Brownlie (2001). Iron deficiency and reduced work capacity: a critical review of the research to determine a causal relationship. The Journal of Nutrition 131(2), 676S-690S.

Haas, J. D., M. Rahn, S. Venkatramanan, G. S. Marquis, M. J. Wenger, L. E. Murray-Kolb, A. S. Wesley, and G. A. Reinhart (2014). Double-fortified salt is efficacious in improving 
indicators of iron deficiency in female Indian tea pickers. The Journal of Nutrition 144(6), 957-964.

Indian Council of Medical Research (2009). Nutrient requirements and recommended dietary allowances for Indians. Technical report, National Institute of Nutrition (NIN).

International Institute for Population Sciences (IIPS) and Macro International (2008). National Family Health Survey (NFHS-3), India, 2005-06: Bihar. Technical report, IIPS, Mumbai.

Lozoff, B. (2007). Iron deficiency and child development. Food \& Nutrition Bulletin 28(Supplement 4), 560S-571S.

Lozoff, B., J. Beard, J. Connor, B. Felt, M. Georgieff, and T. Schallert (2006). Long-lasting neural and behavioral effects of iron deficiency in infancy. Nutrition Reviews 64(s2), S34-S43.

Mudur, G. (2013, June 9). Doubts on fortified midday-meal salt - safe but no clear proof it increases haemoglobin: Scientists. The Telegraph.

Nair, K., G. Brahmam, S. Ranganathan, K. Vijayaraghavan, B. Sivakumar, K. Krishnaswamy, et al. (1998). Impact evaluation of iron \& iodine fortified salt. Indian Journal of Medical $\underline{\text { Research }} \underline{108,203 .}$

Nair, K. M., B. Sesikeran, S. Ranganathan, and B. Sivakumar (1998). Bioeffect and safety of long-term feeding of common salt fortified with iron and iodine (double fortified salt) in rats. $\underline{\text { Nutrition Research 18 }}$ (1), 121-129.

National Institute of Nutrition (India) (2005). Double fortified common salt (DFS) as a tool to control iodine deficiency disorders and iron deficiency anaemia: a report. National Institute of Nutrition.

Neufeld, L., A. García-Guerra, D. Sánchez-Francia, O. Newton-Sánchez, M. D. RamírezVillalobos, and J. Rivera-Dommarco (2002). Hemoglobin measured by hemocue and a reference method in venous and capillary blood: a validation study. Salud pública de México $\underline{44}(3)$, 219-227.

Penninx, B. W., M. Pahor, M. Cesari, A. M. Corsi, R. C. Woodman, S. Bandinelli, J. M. Guralnik, and L. Ferrucci (2004). Anemia is associated with disability and decreased phys- 
ical performance and muscle strength in the elderly. Journal of the American Geriatrics $\underline{\text { Society }} \underline{52}(5), 719-724$.

Peters, R., L. Burch, J. Warner, N. Beckett, R. Poulter, and C. Bulpitt (2008). Haemoglobin, anaemia, dementia and cognitive decline in the elderly, a systematic review. $\underline{B M C}$ $\underline{\text { Geriatrics }} \underline{8}(1), 18$.

Radloff, L. S. (1977). The CES-D scale: a self-report depression scale for research in the general population. Applied Psychological Measurement 1(3), 385-401.

Rajagopalan, S. and M. Vinodkumar (2000). Effects of salt fortified with iron and iodine on the haemoglobin levels and productivity of tea pickers. Food \& Nutrition Bulletin 21(3), 323-329.

Ranganathan, S. and B. Sesikeran (2008). Development of the double-fortified salt from the National Institute of Nutrition. Institute of Food Technologists.

Reddy, K. J. and S. Nair (2014). Double fortified salt and deworming-game changers in the battle against iodine and iron malnutrition in Indian school children. Indian Journal of Community Health $26(6), 175-182$.

Sivakumar, B., G. Brahmam, K. M. Nair, S. Ranganathan, M. V. Rao, K. Vijayaraghavan, and K. Krishnaswamy (2001). Prospects of fortification of salt with iron and iodine. British Journal of Nutrition 85(S2), S167-S173.

Stoltzfus, R. J. (2001). Defining iron-deficiency anemia in public health terms: a time for reflection. The Journal of Nutrition 131(2), 565S-567S.

Thomas, D., E. Frankenberg, J. Friedman, J.-P. Habicht, M. Hakimi, N. Ingwersen, N. Jones, C. McKelvey, G. Pelto, B. Sikoki, et al. (2006). Causal effect of health on labor market outcomes: Experimental evidence. California Center for Population Research.

Thomas, D., E. Frankenberg, J. Friedman, J.-P. Habicht, M. Hakimi, N. J. Jaswadi, G. Pelto, B. Sikoki, T. Seeman, J. P. Smith, et al. (2003). Iron deficiency and the well-being of older adults: Early results from a randomized nutrition intervention. In Population Association of America Annual Meetings, Minneapolis. 
Wegmüller, R., F. Camara, M. B. Zimmermann, P. Adou, and R. F. Hurrell (2006). Salt dualfortified with iodine and micronized ground ferric pyrophosphate affects iron status but not hemoglobin in children in Cote d'Ivoire. The Journal of Nutrition 136(7), 1814-1820.

World Health Organization (2001). Iron Deficiency Anaemia: Assessment, Prevention, and Control. Technical report, UNCDF, UNU and WHO.

Zijp, I. M., O. Korver, and L. B. Tijburg (2000). Effect of tea and other dietary factors on iron absorption. Critical Reviews in Food Science and Nutrition 40(5), 371-398.

Zimmermann, M. B., R. Wegmueller, C. Zeder, N. Chaouki, F. Rohner, M. Saïssi, T. Torresani, and R. F. Hurrell (2004). Dual fortification of salt with iodine and micronized ferric pyrophosphate: a randomized, double-blind, controlled trial. The American Journal of Clinical Nutrition 80(4), 952-959.

Zimmermann, M. B., C. Zeder, N. Chaouki, A. Saad, T. Torresani, and R. F. Hurrell (2003). Dual fortification of salt with iodine and microencapsulated iron: a randomized, double-blind, controlled trial in Moroccan schoolchildren. The American Journal of Clinical Nutrition 77(2), 425-432. 


\section{Figures}

Figure 1: Design of Experiments

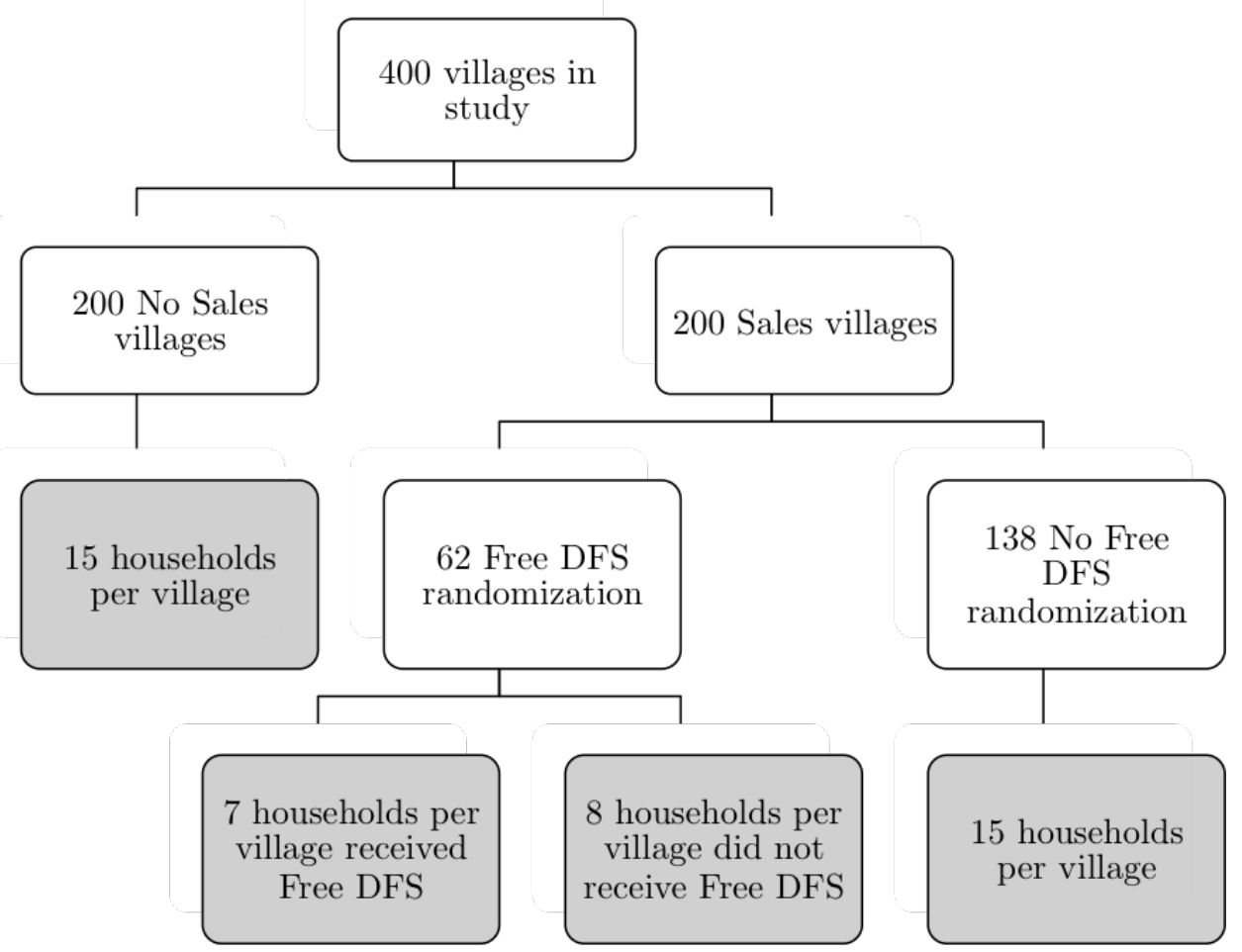


Figure 2: Take-up from Rajasthan

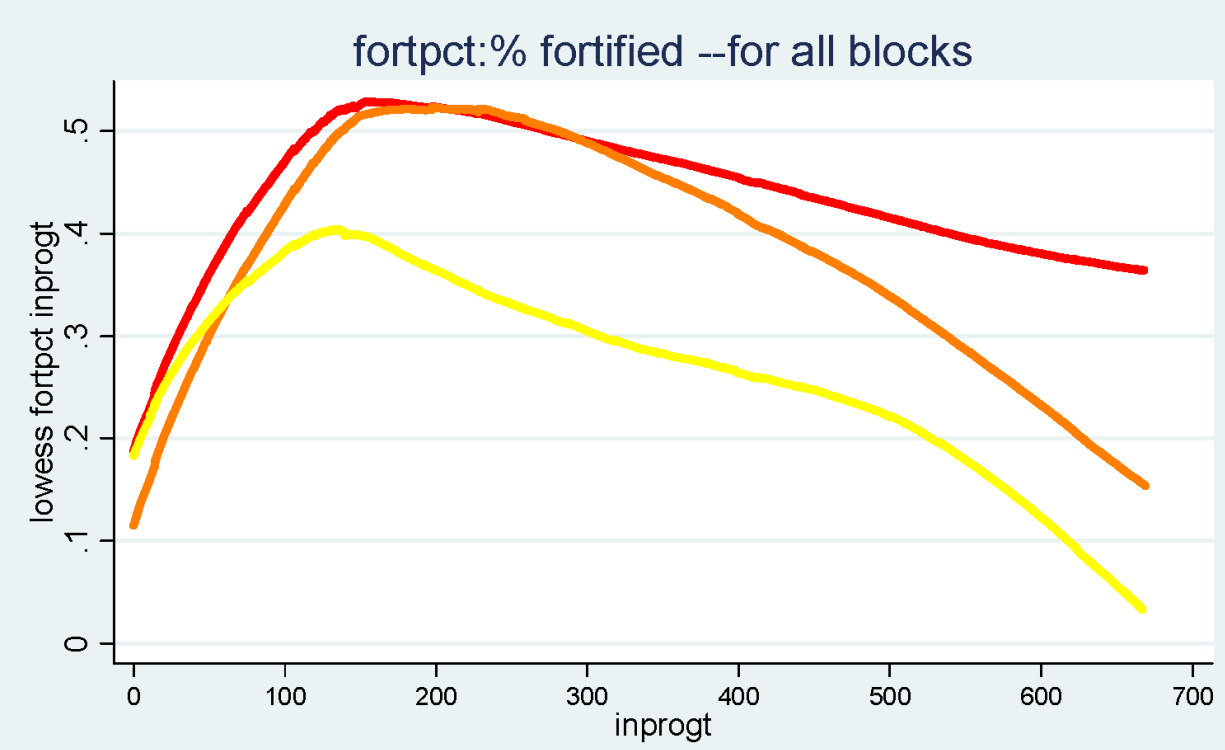

closest chak is treatment

nearby chak is treatment no treat chak nearby

Figure 3: Store Take Up over Time

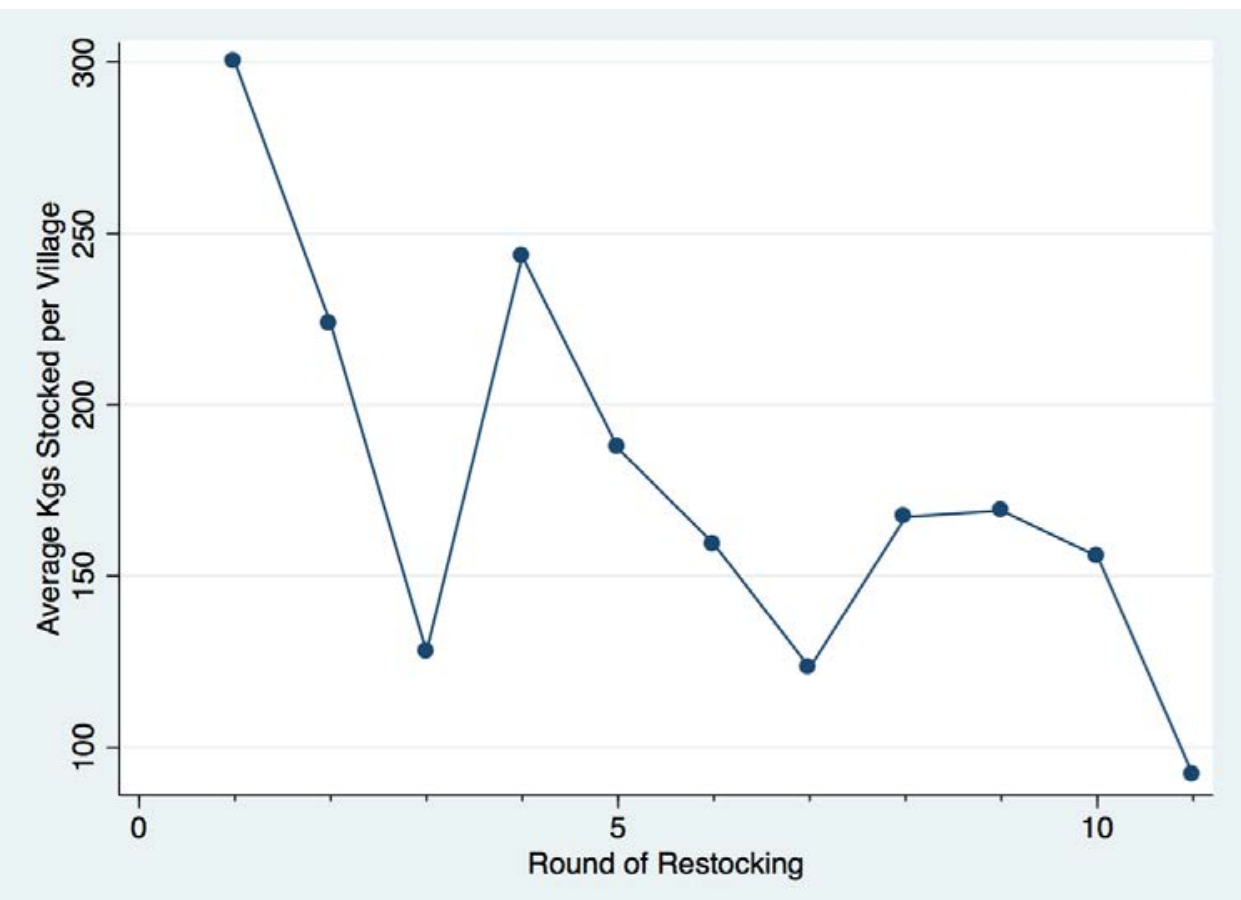




\section{Tables}

Table 1: Outcome Eligibility

\begin{tabular}{ll} 
Topic & Eligible Age \\
\hline Hemoglobin & Ages 6 months and above \\
Anthropometry & All ages; able to stand \\
Physical Fitness & Ages 10 years and older \\
Infant Development & Ages 1-30 months \\
Child Cognition & Ages 5-14 years \\
Adult Cognition & Ages 15-49 years \\
Elderly Cognition & Ages 50 and over
\end{tabular}


Table 2: Balance Checks

\begin{tabular}{|c|c|c|c|c|c|c|c|c|}
\hline & $\begin{array}{c}(1) \\
\text { Control Mean } \\
\text { for Sales } \\
\text { Experiment }\end{array}$ & $\begin{array}{c}(2) \\
\text { Sales } \\
\text { Experiment } \\
\text { (No Free } \\
\text { DFS) }\end{array}$ & $\begin{array}{c}\text { (3) } \\
\text { P-value (Sales } \\
\text { Experiment) }\end{array}$ & $\begin{array}{c}(4) \\
\text { Observations } \\
\text { (Full Sample) }\end{array}$ & $\begin{array}{c}\quad(5) \\
\text { Control Mean } \\
\text { for Free DFS } \\
\text { Experiment }\end{array}$ & $\begin{array}{c}(6) \\
\text { Free DFS } \\
\text { Experiment }\end{array}$ & $\begin{array}{c}(7) \\
\text { P-Value (Free } \\
\text { DFS) }\end{array}$ & $\begin{array}{c}(8) \\
\text { Observations } \\
\text { (Free DFS } \\
\text { Villages) }\end{array}$ \\
\hline \multicolumn{9}{|l|}{ Panel A: Individual-Level Variables } \\
\hline 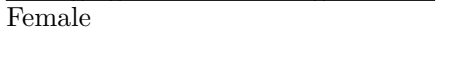 & $\begin{array}{c}0.515 \\
(0.500)\end{array}$ & $\begin{array}{c}0.513 \\
(0.500)\end{array}$ & 0.704 & 39640 & $\begin{array}{c}0.516 \\
(0.500)\end{array}$ & $\begin{array}{c}0.505 \\
(0.500)\end{array}$ & 0.150 & 6301 \\
\hline Age & $\begin{array}{c}28.170 \\
(20.319)\end{array}$ & $\begin{array}{c}27.882 \\
(20.273)\end{array}$ & 0.262 & 39070 & $\begin{array}{c}28.302 \\
(20.543)\end{array}$ & $\begin{array}{c}26.984 \\
(20.000)\end{array}$ & 0.008 & 6225 \\
\hline Elderly Individual (50+ years) & $\begin{array}{c}0.182 \\
(0.386)\end{array}$ & $\begin{array}{c}0.178 \\
(0.382)\end{array}$ & 0.334 & 39641 & $\begin{array}{c}0.186 \\
(0.389)\end{array}$ & $\begin{array}{c}0.162 \\
(0.368)\end{array}$ & 0.014 & 6301 \\
\hline Anemic & $\begin{array}{c}0.447 \\
(0.497)\end{array}$ & $\begin{array}{c}0.445 \\
(0.497)\end{array}$ & 0.963 & 34251 & $\begin{array}{c}0.457 \\
(0.498)\end{array}$ & $\begin{array}{c}0.460 \\
(0.499)\end{array}$ & 0.603 & 5404 \\
\hline Severe Anemia & $\begin{array}{c}0.008 \\
(0.090)\end{array}$ & $\begin{array}{c}0.008 \\
(0.092)\end{array}$ & 0.724 & 34251 & $\begin{array}{c}0.008 \\
(0.087)\end{array}$ & $\begin{array}{c}0.012 \\
(0.108)\end{array}$ & 0.158 & 5404 \\
\hline Hemoglobin Concentration & $\begin{array}{l}12.197 \\
(1.856)\end{array}$ & $\begin{array}{l}12.187 \\
(1.837)\end{array}$ & 0.731 & 34251 & $\begin{array}{l}12.178 \\
(1.862)\end{array}$ & $\begin{array}{l}12.070 \\
(1.914)\end{array}$ & 0.051 & 5404 \\
\hline Standardized Cognition Score & $\begin{array}{c}0.000 \\
(1.000)\end{array}$ & $\begin{array}{l}-0.021 \\
(0.986)\end{array}$ & 0.373 & 32029 & $\begin{array}{c}0.017 \\
(0.980)\end{array}$ & $\begin{array}{l}-0.069 \\
(0.979)\end{array}$ & 0.011 & 5043 \\
\hline Standardized Mental Health Score & $\begin{array}{c}-0.000 \\
(1.000)\end{array}$ & $\begin{array}{c}0.000 \\
(1.013)\end{array}$ & 0.976 & 26101 & $\begin{array}{c}-0.053 \\
(1.050)\end{array}$ & $\begin{array}{c}0.018 \\
(0.993)\end{array}$ & 0.145 & 4100 \\
\hline Standardized Physical Fitness Score & $\begin{array}{c}-0.000 \\
(1.000)\end{array}$ & $\begin{array}{c}0.021 \\
(0.937)\end{array}$ & 0.369 & 15165 & $\begin{array}{l}-0.059 \\
(0.955)\end{array}$ & $\begin{array}{l}-0.070 \\
(0.998)\end{array}$ & 0.720 & 2311 \\
\hline Body Mass Index (BMI) & $\begin{array}{l}18.145 \\
(4.221)\end{array}$ & $\begin{array}{l}18.106 \\
(4.202)\end{array}$ & 0.605 & 34590 & $\begin{array}{l}18.274 \\
(4.351)\end{array}$ & $\begin{array}{l}17.907 \\
(4.574)\end{array}$ & 0.008 & 5459 \\
\hline Completed $5+$ years of schooling & $\begin{array}{l}0.530 \\
(0.499)\end{array}$ & $\begin{array}{c}0.525 \\
(0.499)\end{array}$ & 0.703 & 34874 & $\begin{array}{c}0.528 \\
(0.499)\end{array}$ & $\begin{array}{c}0.484 \\
(0.500)\end{array}$ & 0.044 & 5548 \\
\hline
\end{tabular}


Panel B: Household-Level Variables 30 day Consumption per Capita

Household Head Completed 5+ Years of Schoolin

At least one elderly, anemic person in Household

Number of Household Members

Only Immediate Family Members in Household

Baseline Wealth Index

Household split since Baselin

Panel C: Attrition Measurements

Entire Household Lost to Attrition

Individual Present in Baseline Sample

Baseline Respondent Missing Endline Hemoglobin
2351.154 $(2897.359)$

0.555

$(0.497)$

0.488

6.542

$(3.514)$
0.356

(0.479)

$-0.037$

$(0.653)$

0.146

$(0.353)$

0.039

$(0.194)$

0.819

$(0.385)$

0.215

$(0.411)$

(0.394)

0.034

(0.182)

0.046

$(0.209)$

0.108

$(0.311)$

0.779

(4.003)

2314.514
$(2395.192)$
0.558
$(0.497)$
0.468
$(0.499)$
6.643
$(3.929)$
0.367
$(0.482)$
-0.040
$(0.625)$
0.157
$(0.364)$


0.052
$(0.222)$
0.819
$(0.385)$
0.217
$(0.412)$
0.191
$(0.393)$


0.145
$(0.352)$
0.218
$(0.413)$
0.426
$(0.495)$
3.313
$(7.086)$

$\begin{array}{ccc}0.603 & 5954 & 2326.878 \\ & & (2804.108) \\ 0.565 \\ 0.904 & 5001 & (0.496) \\ & & 0.488 \\ 0.190 & 5906 & (0.500) \\ & & 6.761 \\ 0.339 & 6004 & (4.125) \\ & & 0.341 \\ 0.463 & 5997 & (0.474) \\ & & -0.018 \\ 0.894 & 6002 & (0.637) \\ & & 0.177 \\ 0.322 & 6004 & (0.382) \\ & & \end{array}$

(2626.661)

0.938

923

0.485

0.012

786

$\begin{array}{lll}0.475 & 0.708 & 917\end{array}$

$\begin{array}{lll}(0.500) & 0.949 & 932\end{array}$

(3.988)

$(3.988)$
0.364

0.364

$(0.482)$

-0.016
$(0.765)$

0.226

0.460

930

930

0.996

931

(0.419)

0.054

0.023

0.065

932

0.043

0.044

$(0.206)$
0.814

0.814
$(0.389)$

0.905

48536

0.211

$(0.150)$
0.794

$(0.405)$

0.166

0.085

7832

$(0.408) \quad(0.372)$

0.003

6302

(0.372)

$(0.357)$

0.018

(0.388)

0.611

(0.488)

0.753
$(0.432)$

0.745

(0.437)

6.656
$(7.378)$

0.000

(7.378)

0.000

1063

0.000

725

0.000

0.000

789

1 The table presents summary statistics for all those in our sample for whom we have the respective data. The sample used varies by column. Column 1 ("Control Mean for Sales Experiment") includes all respondents and households who were located in villages that did not receive the Sales intervention. Column 2 ("Sales Experiment (No Free DFS)") includes all those located in villages that were part of the Sales Experiment, excluding households that received the Free DFS Intervention. Column 5 ("Control Mean for Free DFS Experiment") includes all respondents who were in villages where the Free DFS treatment occurred, but in households that did not receive the Free DFS treatment. Column 6 ("Free DFS Experiment") includes those located in households that received the Free DFS Intervention.

2 The sample for "Individual-Level Variables" (except for "Individual in Baseline Sample") includes all baseline respondents from within the respective subsets (refer to footnote 1) that we observe at endline. "Household-Level Variables" includes all households from baseline that we see at endline.

${ }^{3}$ Scores were standardized using the mean from the sales experiment control group at baseline. The cognition outcomes were standardized such that a positive score indicates a higher level of cognition. The physical fitness scores were standardized such that a positive score indicates being more physically fit. The score for the mental health outcomes were standardized such that a positive score indicates a lower level of depression.

${ }^{4}$ Standard deviations are in parentheses. 
Table 3: Sales Experiment - Hemoglobin \& Anemia by Gender and Age

\begin{tabular}{|c|c|c|c|c|c|c|}
\hline Sample: & $\begin{array}{l}(1) \\
\text { All }\end{array}$ & $\begin{array}{c}(2) \\
\text { Female }\end{array}$ & $\begin{array}{l}(3) \\
\text { Male }\end{array}$ & $\begin{array}{c}(4) \\
\text { Child }(<15 \text { years })\end{array}$ & $\begin{array}{c}(5) \\
\text { Adult (15-49 years) }\end{array}$ & $\begin{array}{c}(6) \\
\text { Elderly }(50+\text { years })\end{array}$ \\
\hline \multicolumn{7}{|c|}{ Panel A: Hemoglobin Concentration } \\
\hline Sales village & $\begin{array}{c}0.045 \\
{[0.027]}\end{array}$ & $\begin{array}{c}0.031 \\
{[0.029]}\end{array}$ & $\begin{array}{c}0.061 \\
{[0.033]}\end{array}$ & $\begin{array}{c}0.068 \\
{[0.034]}\end{array}$ & $\begin{array}{c}0.055 \\
{[0.035]}\end{array}$ & $\begin{array}{l}-0.019 \\
{[0.044]}\end{array}$ \\
\hline Q-value & & $(0.160)$ & $(0.150)$ & $(0.242)$ & $(0.242)$ & $(0.488)$ \\
\hline Control Mean & 12.056 & 11.416 & 12.769 & 11.492 & 12.575 & 11.982 \\
\hline \multicolumn{7}{|c|}{ Panel B: Anemia } \\
\hline Sales village & $\begin{array}{l}-0.009 \\
{[0.008]}\end{array}$ & $\begin{array}{l}-0.002 \\
{[0.010]}\end{array}$ & $\begin{array}{l}-0.016 \\
{[0.009]}\end{array}$ & $\begin{array}{l}-0.019 \\
{[0.012]}\end{array}$ & $\begin{array}{l}-0.011 \\
{[0.010]}\end{array}$ & $\begin{array}{c}0.017 \\
{[0.012]}\end{array}$ \\
\hline Q-value & & $(0.739)$ & $(0.201)$ & $(0.428)$ & $(0.428)$ & $(0.428)$ \\
\hline Control Mean & 0.491 & 0.597 & 0.375 & 0.472 & 0.457 & 0.605 \\
\hline Observations & 34732 & 17941 & 16726 & 12775 & 15576 & 6295 \\
\hline \multicolumn{7}{|c|}{ Panel C: Hemoglobin Concentration (Baseline Anemic Only) } \\
\hline Sales village & $\begin{array}{c}0.077 \\
{[0.040]}\end{array}$ & $\begin{array}{c}0.045 \\
{[0.042]}\end{array}$ & $\begin{array}{c}0.145 \\
{[0.055]}\end{array}$ & $\begin{array}{c}0.134 \\
{[0.054]}\end{array}$ & $\begin{array}{c}0.062 \\
{[0.054]}\end{array}$ & $\begin{array}{c}0.048 \\
{[0.064]}\end{array}$ \\
\hline Q-value & & $(0.166)$ & $(0.018)$ & $(0.054)$ & $(0.302)$ & $(0.302)$ \\
\hline Control Mean & 11.364 & 11.027 & 11.917 & 11.248 & 11.544 & 11.205 \\
\hline \multicolumn{7}{|c|}{ Panel D: Anemia (Baseline Anemic Only) } \\
\hline Sales village & $\begin{array}{l}-0.015 \\
{[0.011]}\end{array}$ & $\begin{array}{l}-0.004 \\
{[0.013]}\end{array}$ & $\begin{array}{l}-0.035 \\
{[0.015]}\end{array}$ & $\begin{array}{l}-0.026 \\
{[0.020]}\end{array}$ & $\begin{array}{l}-0.014 \\
{[0.014]}\end{array}$ & $\begin{array}{l}-0.009 \\
{[0.015]}\end{array}$ \\
\hline Q-value & & $(0.643)$ & $(0.048)$ & $(1.000)$ & $(1.000)$ & $(1.000)$ \\
\hline Control Mean & 0.669 & 0.722 & 0.581 & 0.561 & 0.674 & 0.785 \\
\hline Observations & 11505 & 7167 & 4318 & 3535 & 4909 & 3035 \\
\hline
\end{tabular}

\footnotetext{
${ }^{1}$ Standard errors in brackets.
}

${ }^{2}$ Regression includes block-fixed effects. Standard errors are clustered at the village level. The sample includes all respondents present at endline for whom we have the respective outcomes data, excluding Free DFS Households.

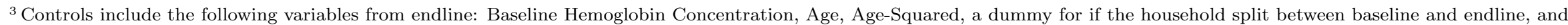

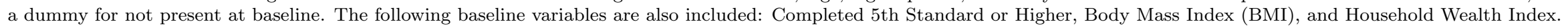
Note: For children under 10, education is for the head of the household.

${ }^{4}$ Anemia thresholds are determined by age and gender, therefore, a dummy for each of these age groups is included in the regressions for anemia. 
Table 4: Free DFS Experiment Compared to Control - Hemoglobin \& Anemia by Gender and Age

\begin{tabular}{|c|c|c|c|c|c|c|c|}
\hline & Sample: & $\begin{array}{l}(1) \\
\text { All }\end{array}$ & $\begin{array}{c}(2) \\
\text { Female }\end{array}$ & $\begin{array}{l}(3) \\
\text { Male }\end{array}$ & $\begin{array}{c}(4) \\
\text { Child }(<15 \text { years })\end{array}$ & $\begin{array}{c}(5) \\
\text { Adult (15-49 years) }\end{array}$ & $\begin{array}{l}(6) \\
\text { Elderly }(50+\text { years })\end{array}$ \\
\hline & Panel A: Hemoglobin Concentration & & & & & & \\
\hline & Household in Free DFS Treatment & 0.044 & 0.054 & -0.008 & 0.097 & 0.041 & -0.136 \\
\hline & & {$[0.049]$} & {$[0.055]$} & {$[0.058]$} & {$[0.057]$} & {$[0.057]$} & {$[0.082]$} \\
\hline & Q-value & & $(1.000)$ & $(1.000)$ & $(0.211)$ & $(0.211)$ & $(0.211)$ \\
\hline & Control Mean & 12.056 & 11.416 & 12.769 & 11.492 & 12.575 & 11.982 \\
\hline & Panel B: Anemia & & & & & & \\
\hline & Household in Free DFS Treatment & -0.015 & -0.018 & -0.008 & -0.027 & -0.011 & 0.006 \\
\hline & & {$[0.015]$} & {$[0.018]$} & {$[0.017]$} & {$[0.019]$} & {$[0.016]$} & {$[0.023]$} \\
\hline & Q-value & & $(1.000)$ & $(1.000)$ & $(0.321)$ & $(0.528)$ & $(0.639)$ \\
\hline & Control Mean & 0.491 & 0.597 & 0.375 & 0.472 & 0.457 & 0.605 \\
\hline & Observations & 21623 & 11163 & 10412 & 7960 & 9670 & 3925 \\
\hline & Panel C: Hemoglobin Concentration (Baseline Anemic Only) & & & & & & \\
\hline & Household in Free DFS Treatment & 0.018 & 0.086 & -0.119 & 0.079 & 0.059 & -0.159 \\
\hline 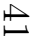 & & {$[0.072]$} & {$[0.075]$} & {$[0.100]$} & {$[0.096]$} & {$[0.094]$} & {$[0.108]$} \\
\hline & Q-value & & $(0.340)$ & $(0.340)$ & $(1.000)$ & $(1.000)$ & $(1.000)$ \\
\hline & Control Mean & 11.364 & 11.027 & 11.917 & 11.248 & 11.544 & 11.205 \\
\hline & Panel D: Anemia (Baseline Anemic Only) & & & & & & \\
\hline & $\overline{\text { Household in Free DFS Treatment }}$ & -0.002 & -0.017 & 0.027 & 0.002 & -0.004 & -0.012 \\
\hline & & {$[0.023]$} & {$[0.025]$} & {$[0.030]$} & {$[0.033]$} & {$[0.029]$} & {$[0.028]$} \\
\hline & Q-value & & $(0.942)$ & $(0.942)$ & $(1.000)$ & $(1.000)$ & $(1.000)$ \\
\hline & Control Mean & 0.669 & 0.722 & 0.581 & 0.561 & 0.674 & 0.785 \\
\hline & Observations & 7192 & 4461 & 2717 & 2202 & 3043 & 1913 \\
\hline
\end{tabular}

Standard errors in brackets.

${ }^{2}$ Standard errors are cluster at the village level. The sample includes all respondents located in the Sales Experiment control group or Free DFS households, who were present at endline and for whom we have the respective outcomes data.

${ }^{3}$ Controls include the following variables from endline: Baseline Hemoglobin Concentration, Age, Age-Squared, a dummy for if the household split between baseline and endline, and

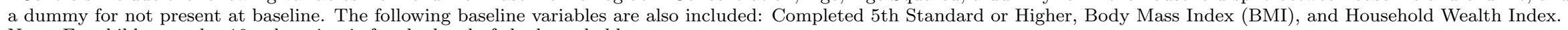
Note: For children under 10, education is for the head of the household.

${ }^{4}$ Anemia thresholds are determined by age and gender, therefore, a dummy for each of these age groups is included in the regressions for anemia. 
Table 5: Free DFS Experiment in Free DFS Villages - Hemoglobin \& Anemia by Gender and Age

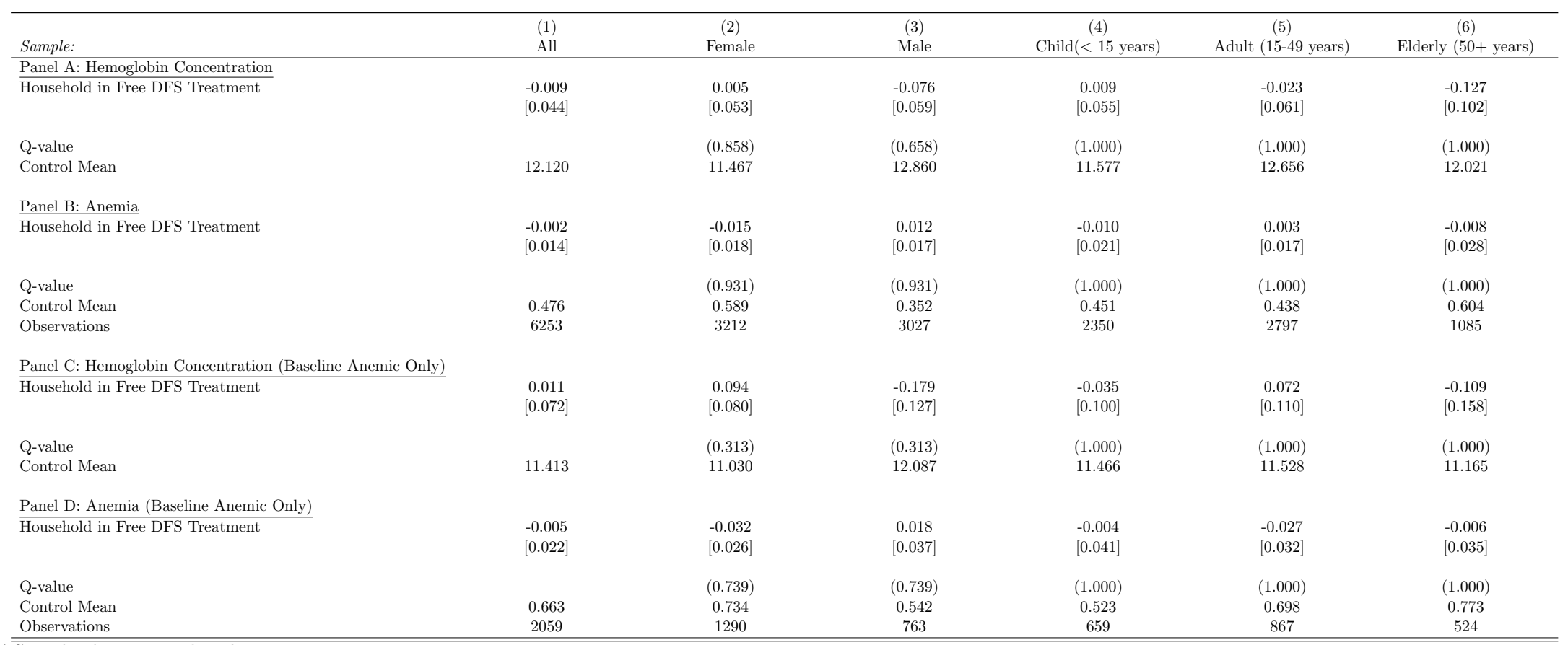

Standard errors in brackets.

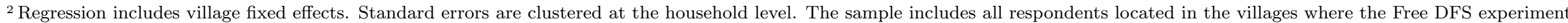
took place, who were present at endline and for whom we have the respective outcomes data.

${ }^{3}$ Controls include the following variables from endline: Baseline Hemoglobin Concentration, Age, Age-Squared, a dummy for if the household split between baseline and endline, and

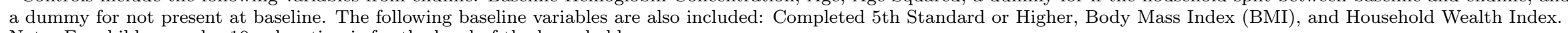
Note: For children under 10, education is for the head of the household.

${ }^{4}$ Anemia thresholds are determined by age and gender, therefore, a dummy for each of these age groups is included in the regressions for anemia. 
Table 6: First Stage for Salt Consumption - Currently Using or Penultimately Used DFS

\begin{tabular}{|c|c|c|c|c|c|c|}
\hline & (1) & $(2)$ & (3) & $(4)$ & (5) & $(6)$ \\
\hline Sample: & All & Female & Male & All Anemic ${ }^{2}$ & Anemic Female $^{2}$ & Anemic Male $^{2}$ \\
\hline Sales village & 0.164 & 0.166 & 0.164 & 0.165 & 0.162 & 0.171 \\
\hline & [0.019] & {$[0.019]$} & [0.019] & {$[0.021]$} & {$[0.022]$} & {$[0.023]$} \\
\hline Household in Free DFS Treatment & $\begin{array}{c}0.494 \\
{[0.045]}\end{array}$ & $\begin{array}{c}0.477 \\
{[0.049]}\end{array}$ & $\begin{array}{c}0.511 \\
{[0.042]}\end{array}$ & $\begin{array}{c}0.523 \\
{[0.049]}\end{array}$ & $\begin{array}{c}0.504 \\
{[0.053]}\end{array}$ & $\begin{array}{c}0.552 \\
{[0.047]}\end{array}$ \\
\hline $\begin{array}{l}\text { P-value: Sales Experiment }+ \\
\text { Free DFS Household }=0\end{array}$ & 0.000 & 0.000 & 0.000 & 0.000 & 0.000 & 0.000 \\
\hline Control Mean & 0.049 & 0.049 & 0.049 & 0.047 & 0.050 & 0.042 \\
\hline Observations & 28126 & 14208 & 13564 & 8925 & 5536 & 3374 \\
\hline
\end{tabular}

${ }^{1}$ Standard errors in brackets.

2 The Anemic Female and Anemic Male groups refer to females and males (respectively) who were anemic at baseline. All anemic includes both males and females who were anemic at baseline.

${ }^{3}$ Standard errors are clustered at the village level and the regression includes all respondents who were present at endline and for whom we have the respective outcomes data.

${ }^{4}$ Controls include the following variables from endline: Age, Age-Squared, a dummy for if the household split between baseline and endline, and a dummy for not present at baseline. The following baseline variables are also included: Baseline Hemoglobin Concentration, Completed 5th Standard or Higher, Body Mass Index (BMI), and Household Wealth Index. Note: For children under 10, education is for the head of the household. 
Table 7: All Health Outcomes - 2SLS Estimates

\begin{tabular}{|c|c|c|c|c|c|c|}
\hline Sample: & $\begin{array}{l}(1) \\
\text { All }\end{array}$ & $\begin{array}{c}(2) \\
\text { Female }\end{array}$ & $\begin{array}{c}(3) \\
\text { Male }\end{array}$ & $\begin{array}{c}(4) \\
\text { All Anemic } \\
\end{array}$ & $\begin{array}{c}(5) \\
\text { Anemic Female }^{2} \\
\end{array}$ & $\begin{array}{c}(6) \\
\text { Anemic } \text { Male }^{2}\end{array}$ \\
\hline \multicolumn{7}{|l|}{ Panel A: Hemoglobin Concentration } \\
\hline Currently Using or Penultimately Used DFS & $\begin{array}{c}0.032 \\
{[0.089]}\end{array}$ & $\begin{array}{c}0.043 \\
{[0.100]}\end{array}$ & $\begin{array}{l}-0.016 \\
{[0.105]}\end{array}$ & $\begin{array}{c}0.020 \\
{[0.126]}\end{array}$ & $\begin{array}{c}0.122 \\
{[0.138]}\end{array}$ & $\begin{array}{l}-0.113 \\
{[0.164]}\end{array}$ \\
\hline Control Mean & 12.056 & 11.416 & 12.769 & 11.364 & 11.027 & 11.917 \\
\hline \multicolumn{7}{|l|}{ Panel B: Anemia } \\
\hline Currently Using or Penultimately Used DFS & $\begin{array}{l}-0.014 \\
{[0.028]}\end{array}$ & $\begin{array}{l}-0.007 \\
{[0.033]}\end{array}$ & $\begin{array}{l}-0.014 \\
{[0.032]}\end{array}$ & $\begin{array}{l}-0.008 \\
{[0.040]}\end{array}$ & $\begin{array}{l}-0.007 \\
{[0.045]}\end{array}$ & $\begin{array}{l}-0.008 \\
{[0.049]}\end{array}$ \\
\hline Observations & 23215 & 12057 & 11119 & 7731 & 4840 & 2876 \\
\hline \multicolumn{7}{|l|}{ Panel C: Standardized Cognition Score } \\
\hline$\overline{\text { Currently Using or Penultimately Used DFS }}$ & $\begin{array}{l}-0.053 \\
{[0.058]}\end{array}$ & $\begin{array}{l}-0.066 \\
{[0.074]}\end{array}$ & $\begin{array}{l}-0.065 \\
{[0.065]}\end{array}$ & $\begin{array}{l}-0.105 \\
{[0.077]}\end{array}$ & $\begin{array}{l}-0.145 \\
{[0.089]}\end{array}$ & $\begin{array}{l}-0.061 \\
{[0.108]}\end{array}$ \\
\hline Control Mean & -0.015 & -0.272 & 0.247 & -0.115 & -0.358 & 0.274 \\
\hline Observations & 19932 & 10090 & 9619 & 6302 & 3926 & 2364 \\
\hline \multicolumn{7}{|l|}{ Panel D: Standardized Physical Fitness Score } \\
\hline$\overline{\text { Currently Using or Penultimately Used DFS }}$ & $\begin{array}{c}-0.059 \\
{[0.103]}\end{array}$ & $\begin{array}{l}-0.109 \\
{[0.116]}\end{array}$ & $\begin{array}{l}-0.000 \\
{[0.109]}\end{array}$ & $\begin{array}{l}-0.079 \\
{[0.126]}\end{array}$ & $\begin{array}{l}-0.113 \\
{[0.140]}\end{array}$ & $\begin{array}{l}-0.001 \\
{[0.177]}\end{array}$ \\
\hline Control Mean & -0.422 & -0.537 & -0.259 & -0.487 & -0.558 & -0.330 \\
\hline Observations & 10278 & 6082 & 4189 & 3630 & 2584 & 1043 \\
\hline \multicolumn{7}{|l|}{ Panel E: Standardized Mental Health Score } \\
\hline Currently Using or Penultimately Used DFS & $\begin{array}{c}-0.043 \\
{[0.070]}\end{array}$ & $\begin{array}{c}0.004 \\
{[0.096]}\end{array}$ & $\begin{array}{c}-0.102 \\
{[0.072]}\end{array}$ & $\begin{array}{l}-0.028 \\
{[0.100]}\end{array}$ & $\begin{array}{l}-0.020 \\
{[0.119]}\end{array}$ & $\begin{array}{c}-0.026 \\
{[0.112]}\end{array}$ \\
\hline Control Mean & -0.090 & -0.315 & 0.170 & -0.194 & -0.361 & 0.123 \\
\hline Observations & 17764 & 9536 & 8210 & 6164 & 4096 & 2061 \\
\hline
\end{tabular}

1 Standard errors in brackets.

${ }^{2}$ The Anemic Female and Anemic Male groups refer to females and males (respectively) who were anemic at baseline. All anemic includes both males and females who were anemic at baseline.

${ }^{3}$ Standard errors are clustered at the village level and the regression includes all respondents who were present at endline and for whom we have the respective outcomes data. Currently using DFS or Penultimately Used DFS is instrumented by a dummy for Sales Experiment and a dummy for Free DFS Households.

${ }^{4}$ Controls include the following variables from endline: Age, Age-Squared, a dummy for if the household split between baseline and endline, and a dummy for not present at baseline. The following baseline variables are also included: Baseline Hemoglobin Concentration, Completed 5th Standard or Higher, Body Mass Index (BMI), and Household Wealth Index. Note: For children under 10, education is for the head of the household.

${ }^{5}$ Scores were standardized using the mean from the sales experiment control group at baseline. The cognition outcomes were standardized such that a positive score indicates a higher level of cognition. The physical fitness scores were standardized such that a positive score indicates being more physically fit. The score for the mental health outcomes were standardized such that a positive score indicates a lower level of depression.

${ }^{6}$ Anemia thresholds are determined by age and gender, therefore, a dummy for each of these age groups is included in the regressions for anemia. 
Table 8a: Health Outcomes - Standardized Cognition Scores

\begin{tabular}{|c|c|c|c|c|c|c|}
\hline Sample: & $\begin{array}{l}(1) \\
\text { All }\end{array}$ & $\begin{array}{c}(2) \\
\text { Female }\end{array}$ & $\begin{array}{l}\text { (3) } \\
\text { Male }\end{array}$ & $\begin{array}{c}(4) \\
\text { Child }(<15 \text { years })\end{array}$ & $\begin{array}{c}(5) \\
\text { Adult (15-49 vears) }\end{array}$ & $\begin{array}{ll}(6) & \\
\text { Elderly } & (50+\text { years })\end{array}$ \\
\hline \multicolumn{7}{|l|}{ Panel A: Sales Experiment } \\
\hline$\overline{\text { Sales village }}$ & $\begin{array}{c}0.008 \\
{[0.021]}\end{array}$ & $\begin{array}{c}0.006 \\
{[0.025]}\end{array}$ & $\begin{array}{c}0.006 \\
{[0.022]}\end{array}$ & $\begin{array}{c}0.024 \\
{[0.024]}\end{array}$ & $\begin{array}{c}0.012 \\
{[0.022]}\end{array}$ & $\begin{array}{c}0.000 \\
{[0.035]}\end{array}$ \\
\hline Q-value & $(1.000)$ & $(1.000)$ & $(0.794)$ & $(0.304)$ & $(1.000)$ & $(0.974)$ \\
\hline Control Mean & -0.015 & -0.272 & 0.247 & 0.258 & -0.442 & 0.522 \\
\hline Observations & 32471 & 16292 & 15774 & 11716 & 14643 & 5704 \\
\hline \multicolumn{7}{|c|}{ Panel B: Sales Experiment (Baseline Anemic Only) } \\
\hline Sales village & $\begin{array}{c}0.014 \\
{[0.028]}\end{array}$ & $\begin{array}{c}0.001 \\
{[0.031]}\end{array}$ & $\begin{array}{c}0.028 \\
{[0.036]}\end{array}$ & $\begin{array}{c}0.024 \\
{[0.039]}\end{array}$ & $\begin{array}{l}-0.001 \\
{[0.025]}\end{array}$ & $\begin{array}{l}-0.014 \\
{[0.047]}\end{array}$ \\
\hline Q-value & $(1.000)$ & $(1.000)$ & $(1.000)$ & $(1.000)$ & $(1.000)$ & $(1.000)$ \\
\hline Control Mean & -0.115 & -0.358 & 0.274 & 0.106 & -0.549 & 0.377 \\
\hline Observations & 10240 & 6318 & 3902 & 2976 & 4550 & 2689 \\
\hline \multicolumn{7}{|l|}{ Panel C: Free DFS Households } \\
\hline Household in Free DFS Treatment & $\begin{array}{l}-0.048 \\
{[0.033]}\end{array}$ & $\begin{array}{l}-0.052 \\
{[0.039]}\end{array}$ & $\begin{array}{l}-0.060 \\
{[0.036]}\end{array}$ & $\begin{array}{c}0.033 \\
{[0.042]}\end{array}$ & $\begin{array}{l}-0.036 \\
{[0.034]}\end{array}$ & $\begin{array}{l}-0.137 \\
{[0.070]}\end{array}$ \\
\hline Q-value & $(0.313)$ & $(0.381)$ & $(0.400)$ & $(0.723)$ & $(0.804)$ & $(0.185)$ \\
\hline Control Mean & -0.015 & -0.272 & 0.247 & 0.258 & -0.442 & 0.522 \\
\hline \multicolumn{7}{|c|}{ Panel D: Free DFS Households (Baseline Anemic Only) } \\
\hline Household in Free DFS Treatment & $\begin{array}{l}-0.073 \\
{[0.046]}\end{array}$ & $\begin{array}{l}-0.089 \\
{[0.048]}\end{array}$ & $\begin{array}{l}-0.074 \\
{[0.071]}\end{array}$ & $\begin{array}{c}0.057 \\
{[0.067]}\end{array}$ & $\begin{array}{l}-0.065 \\
{[0.045]}\end{array}$ & $\begin{array}{l}-0.229 \\
{[0.087]}\end{array}$ \\
\hline Q-value & $(0.538)$ & $(0.256)$ & (1.000) & (1.000) & $(0.204)$ & $(0.030)$ \\
\hline Control Mean & -0.115 & -0.358 & 0.274 & 0.106 & -0.549 & 0.377 \\
\hline Observations & 5873 & 3622 & 2239 & 1679 & 2623 & 1547 \\
\hline
\end{tabular}

Standard errors in brackets.

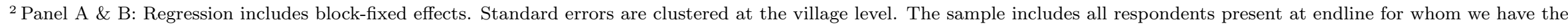
respective outcomes data, excluding Free DFS Households. Panel C \& D: Standard errors are cluster at the village level. The sample includes all respondents located in the Sales Experiment control group or Free DFS households, who were present at endline and for whom we have the respective outcomes data.

${ }^{3}$ Controls include the following variables from endline: Baseline Hemoglobin Concentration, Age, Age-Squared, a dummy for if the household split between baseline and endline, and

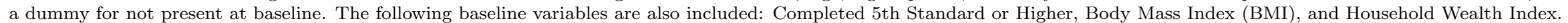
Note: For children under 10 , education is for the head of the household. 
Table 8b: Health Outcomes - Standardized Physical Fitness

\begin{tabular}{|c|c|c|c|c|c|c|}
\hline Sample: & $\begin{array}{l}(1) \\
\text { All }\end{array}$ & $\begin{array}{c}(2) \\
\text { Female }\end{array}$ & $\begin{array}{c}(3) \\
\text { Male }\end{array}$ & $\begin{array}{c}(4) \\
\text { Child }(<15 \text { years })\end{array}$ & $\begin{array}{c}(5) \\
\text { Adult (15-49 years) }\end{array}$ & $\begin{array}{c}(6) \\
\text { Elderly }(50+\text { years })\end{array}$ \\
\hline \multicolumn{7}{|l|}{ Panel A: Sales Experiment } \\
\hline$\overline{\text { Sales village }}$ & $\begin{array}{l}-0.021 \\
{[0.034]}\end{array}$ & $\begin{array}{l}-0.014 \\
{[0.038]}\end{array}$ & $\begin{array}{l}-0.042 \\
{[0.040]}\end{array}$ & $\begin{array}{l}-0.048 \\
{[0.051]}\end{array}$ & $\begin{array}{l}-0.003 \\
{[0.039]}\end{array}$ & $\begin{array}{l}-0.047 \\
{[0.046]}\end{array}$ \\
\hline Q-value & $(1.000)$ & $(1.000)$ & $(0.794)$ & $(0.304)$ & $(1.000)$ & $(0.974)$ \\
\hline Control Mean & -0.422 & -0.537 & -0.259 & -0.313 & -0.396 & -0.566 \\
\hline Observations & 16950 & 9886 & 7049 & 2725 & 10444 & 3777 \\
\hline \multicolumn{7}{|c|}{ Panel B: Sales Experiment (Baseline Anemic Only) } \\
\hline Sales village & $\begin{array}{l}-0.033 \\
{[0.038]}\end{array}$ & $\begin{array}{l}-0.027 \\
{[0.042]}\end{array}$ & $\begin{array}{l}-0.058 \\
{[0.055]}\end{array}$ & $\begin{array}{l}-0.057 \\
{[0.085]}\end{array}$ & $\begin{array}{l}-0.021 \\
{[0.044]}\end{array}$ & $\begin{array}{l}-0.056 \\
{[0.058]}\end{array}$ \\
\hline Q-value & $(1.000)$ & $(1.000)$ & $(1.000)$ & $(1.000)$ & $(1.000)$ & $(1.000)$ \\
\hline Control Mean & -0.487 & -0.558 & -0.330 & -0.337 & -0.433 & -0.661 \\
\hline Observations & 6016 & 4196 & 1813 & 818 & 3509 & 1689 \\
\hline \multicolumn{7}{|l|}{ Panel C: Free DFS Households } \\
\hline Household in Free DFS Treatment & $\begin{array}{l}-0.085 \\
{[0.060]}\end{array}$ & $\begin{array}{l}-0.094 \\
{[0.066]}\end{array}$ & $\begin{array}{l}-0.088 \\
{[0.067]}\end{array}$ & $\begin{array}{l}-0.206 \\
{[0.089]}\end{array}$ & $\begin{array}{l}-0.086 \\
{[0.064]}\end{array}$ & $\begin{array}{c}0.051 \\
{[0.090]}\end{array}$ \\
\hline Q-value & $(0.313)$ & $(0.381)$ & $(0.400)$ & $(0.069)$ & $(0.804)$ & $(1.000)$ \\
\hline Control Mean & -0.422 & -0.537 & -0.259 & -0.313 & -0.396 & -0.566 \\
\hline Observations & 9724 & 5698 & 4017 & 1540 & 6003 & 2180 \\
\hline \multicolumn{7}{|c|}{ Panel D: Free DFS Households (Baseline Anemic Only) } \\
\hline Household in Free DFS Treatment & $\begin{array}{l}-0.080 \\
{[0.072]}\end{array}$ & $\begin{array}{l}-0.096 \\
{[0.082]}\end{array}$ & $\begin{array}{l}-0.053 \\
{[0.115]}\end{array}$ & $\begin{array}{c}0.013 \\
{[0.150]}\end{array}$ & $\begin{array}{l}-0.149 \\
{[0.078]}\end{array}$ & $\begin{array}{l}-0.007 \\
{[0.130]}\end{array}$ \\
\hline Q-value & $(0.538)$ & $(0.325)$ & $(1.000)$ & $(1.000)$ & $(0.204)$ & $(1.000)$ \\
\hline Control Mean & -0.487 & -0.558 & -0.330 & -0.337 & -0.433 & -0.661 \\
\hline Observations & 3443 & 2394 & 1046 & 454 & 2008 & 981 \\
\hline
\end{tabular}

1 Standard errors in brackets.

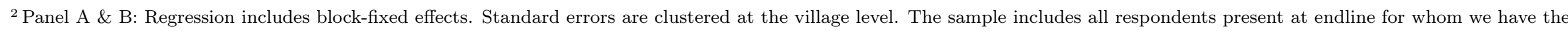
respective outcomes data, excluding Free DFS Households. Panel C \& D: Standard errors are cluster at the village level. The sample includes all respondents located in the Sales Experiment control group or Free DFS households, who were present at endline and for whom we have the respective outcomes data.

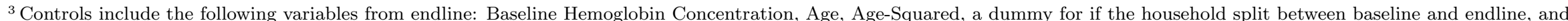

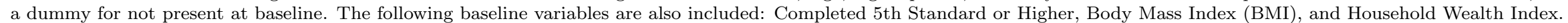
Note: For children under 10, education is for the head of the household. 
Table 8c: Health Outcomes - Standardized Mental Health

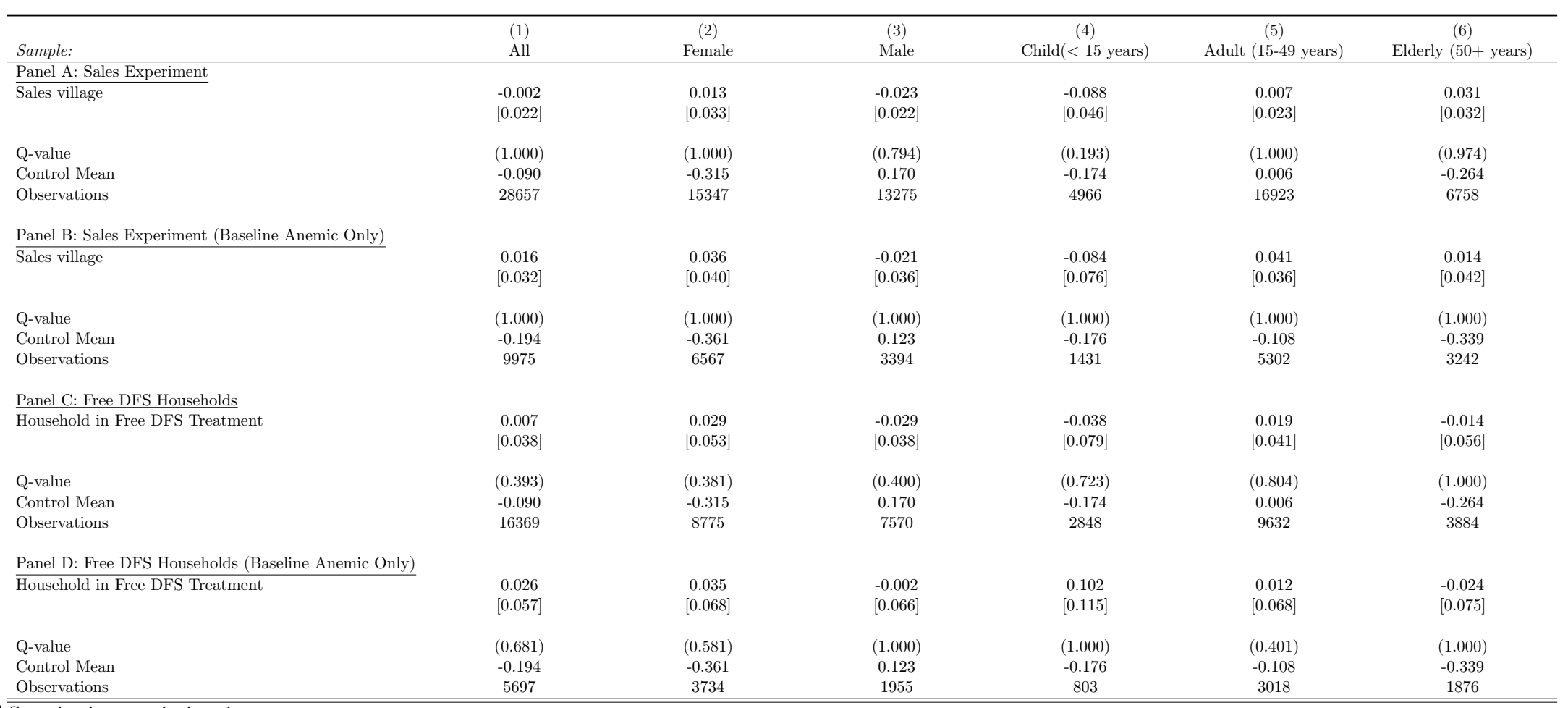

Standard errors in brackets.

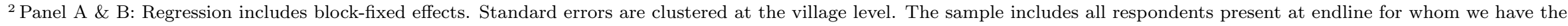
respective outcomes data, excluding Free DFS Households. Panel C \& D: Standard errors are cluster at the village level. The sample includes all respondents located in the Sales Experiment control group or Free DFS households, who were present at endline and for whom we have the respective outcomes data.

${ }^{3}$ Controls include the following variables from endline: Baseline Hemoglobin Concentration, Age, Age-Squared, a dummy for if the household split between baseline and endline, and a dummy for not present at baseline. The following baseline variables are also included: Completed 5th Standard or Higher, Body Mass Index (BMI), and Household Wealth Index. Note: For children under 10, education is for the head of the household. 
Table 9: Effect on Hemoglobin Level and Anemia Indicator (All Blocks) - Rajasthan

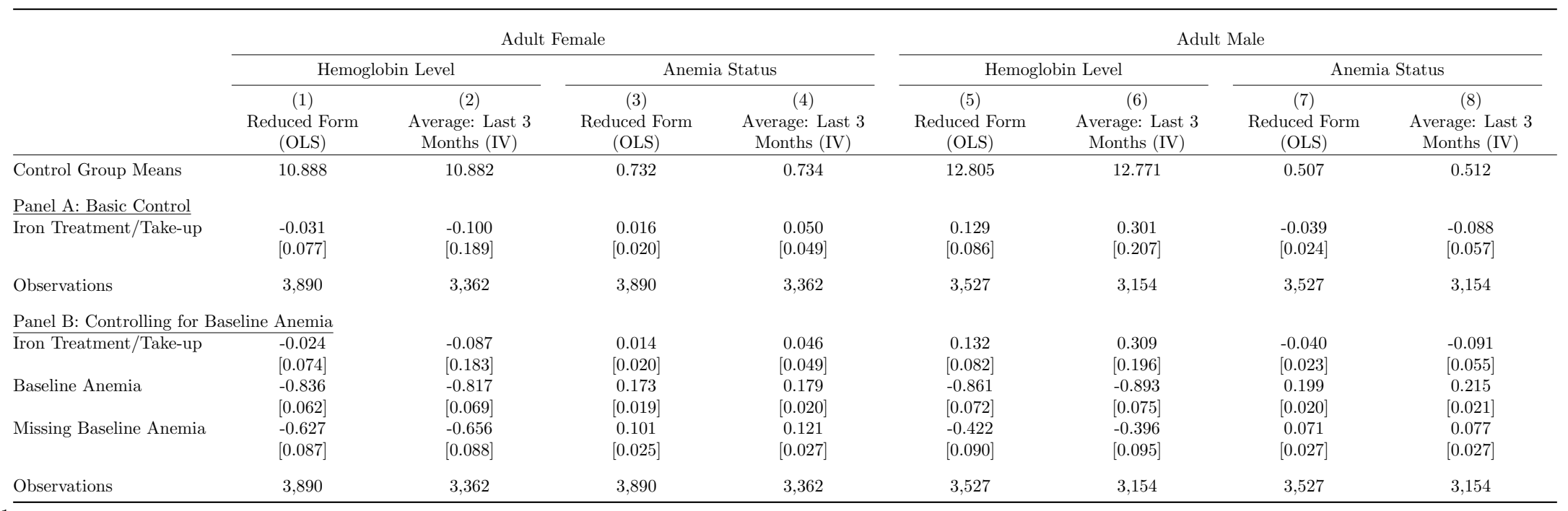

1 Standard errors in brackets. Standard errors are clustered at the village level

${ }^{2}$ The controls in Panel A include Age, Age $^{2}$, and block dummies. Panel B includes missing values. All IV regressions in Panels A-B use original treatment status as the instrument.

${ }^{3}$ Average take-up in the last 3 months and during the treatment period is from the monthly CHS survey. 
Table 10: Adolescent (13-17 years) Estimates

\begin{tabular}{|c|c|c|c|c|}
\hline \multirow[b]{3}{*}{ Sample: } & \multicolumn{2}{|c|}{ Hemoglobin Concentration } & \multicolumn{2}{|c|}{ Anemia } \\
\hline & $(1)$ & $(2)$ & $(3)$ & $(4)$ \\
\hline & Adolescents & Anemic Adolescents & Adolescents & Anemic Adolescents \\
\hline \multicolumn{5}{|l|}{ Panel A: - Sales Experiment (OLS) } \\
\hline \multirow[t]{2}{*}{ Sales village } & 0.044 & 0.151 & -0.005 & -0.024 \\
\hline & {$[0.052]$} & {$[0.096]$} & {$[0.017]$} & {$[0.028]$} \\
\hline Q-value & $(0.360)$ & $(0.211)$ & $(0.494)$ & $(1.000)$ \\
\hline Observations & 4015 & 1276 & 4012 & 1276 \\
\hline \multicolumn{5}{|c|}{ Panel B: Free DFS Experiment Compared to Control (OLS) } \\
\hline \multirow[t]{2}{*}{ Household in Free DFS Treatment } & 0.156 & 0.071 & -0.059 & -0.000 \\
\hline & {$[0.103]$} & {$[0.176]$} & {$[0.025]$} & {$[0.040]$} \\
\hline Q-value & $(0.211)$ & $(1.000)$ & $(0.086)$ & $(1.000)$ \\
\hline Observations & 2485 & 792 & 2484 & 792 \\
\hline \multicolumn{5}{|c|}{ Panel C: Free DFS Experiment within Free DFS Villages (OLS) } \\
\hline Household in Free DFS Treatment & 0.050 & -0.096 & -0.050 & -0.001 \\
\hline Q-value & $(1.000)$ & $(1.000)$ & $(1.000)$ & $(1.000)$ \\
\hline Observations & 704 & 238 & 704 & 238 \\
\hline \multicolumn{5}{|l|}{ Panel D: 2SLS Estimates } \\
\hline \multirow[t]{2}{*}{ Currently Using or Penultimately Used DFS } & 0.410 & 0.211 & -0.121 & 0.020 \\
\hline & {$[0.186]$} & {$[0.305]$} & {$[0.050]$} & {$[0.069]$} \\
\hline Control Mean & 12.386 & 11.644 & 0.467 & 0.636 \\
\hline Observations & 2682 & 849 & 2680 & 849 \\
\hline
\end{tabular}

${ }^{1}$ Standard errors in brackets.

${ }^{2}$ Panel A: Regression includes block-fixed effects. Standard errors are clustered at the village level. The sample includes all respondents present at endline for whom we have the respective outcomes data, excluding Free DFS Households. Panel B: Standard errors are cluster at the village level. The sample includes all respondents located in the Sales Experiment control group or Free DFS households, who were present at endline and for whom we have the respective outcomes data. Panel C: Regression includes village fixed effects. Standard errors are clustered at the household level. The sample includes all respondents located in the villages where the Free DFS experiment took place, who were present at endline and for whom we have the respective outcomes data. Panel D: Standard errors are clustered at the village level and the regression includes all respondents who were present at endline and for whom we have the respective outcomes data. Currently using DFS or Penultimately Used DFS is instrumented by a dummy for Sales Experiment and a dummy for Free DFS Households

${ }^{3}$ Controls include the following variables from endline: Baseline Hemoglobin Concentration, Age, Age-Squared, a dummy for if the household split between baseline and endline, and a dummy for not present at baseline. The following baseline variables are also included: Completed 5th Standard or Higher, Body Mass Index (BMI), and Household Wealth Index. Note: For children under 10, education is for the head of the household.

${ }^{4}$ Anemia thresholds are determined by age and gender, therefore, a dummy for each of these age groups is included in the regressions for anemia. 


\section{Appendix}

Table 11: Hemoglobin and Anemia

\begin{tabular}{|c|c|c|c|c|c|c|}
\hline & (1) & $(2)$ & (3) & (4) & (5) & (6) \\
\hline Sample: & All & All Anemic ${ }^{2}$ & Female & Male & Anemic Female $^{2}$ & Anemic Male \\
\hline \multirow[t]{2}{*}{ Sales village } & 0.056 & 0.115 & 0.034 & 0.076 & 0.060 & 0.173 \\
\hline & {$[0.056]$} & {$[0.090]$} & {$[0.059]$} & {$[0.062]$} & {$[0.097]$} & {$[0.115]$} \\
\hline \multirow[t]{2}{*}{ Free DFS Village } & 0.035 & -0.028 & 0.028 & 0.054 & -0.043 & 0.045 \\
\hline & {$[0.043]$} & {$[0.072]$} & {$[0.046]$} & {$[0.056]$} & {$[0.076]$} & {$[0.104]$} \\
\hline \multirow[t]{2}{*}{ Movie Experiment } & 0.006 & 0.064 & 0.022 & -0.018 & 0.028 & 0.130 \\
\hline & {$[0.042]$} & {$[0.063]$} & {$[0.045]$} & {$[0.051]$} & {$[0.064]$} & {$[0.086]$} \\
\hline \multirow[t]{2}{*}{ Flyer Promotion Experiment } & 0.003 & -0.039 & -0.022 & 0.015 & -0.004 & -0.045 \\
\hline & {$[0.044]$} & {$[0.071]$} & {$[0.048]$} & {$[0.049]$} & {$[0.075]$} & {$[0.096]$} \\
\hline \multirow[t]{2}{*}{ Store Incentive - All Kiranas } & -0.043 & -0.062 & 0.001 & -0.077 & -0.028 & -0.104 \\
\hline & {$[0.048]$} & {$[0.069]$} & {$[0.050]$} & {$[0.058]$} & {$[0.073]$} & {$[0.102]$} \\
\hline \multirow[t]{2}{*}{ Store Incentive - 1 Kirana } & -0.015 & -0.002 & 0.034 & -0.037 & 0.020 & -0.028 \\
\hline & {$[0.045]$} & {$[0.071]$} & {$[0.048]$} & {$[0.056]$} & {$[0.073]$} & {$[0.097]$} \\
\hline \multirow[t]{2}{*}{ Movie Treatment - Main Control } & 0.018 & 0.004 & 0.039 & -0.004 & 0.021 & 0.018 \\
\hline & {$[0.042]$} & {$[0.062]$} & {$[0.044]$} & {$[0.051]$} & {$[0.063]$} & {$[0.079]$} \\
\hline Baseline Hemoglobin Concentration & {$[0.007]$} & {$[0.015]$} & {$[0.010]$} & {$[0.011]$} & {$[0.019]$} & {$[0.025]$} \\
\hline Control Mean & 12.056 & 11.364 & 11.416 & 12.769 & 11.027 & 11.917 \\
\hline Observations & 35004 & 11505 & 17941 & 16726 & 7167 & 4318 \\
\hline
\end{tabular}

${ }^{1}$ Standard errors in brackets.

${ }^{2}$ Regression includes block-fixed effects. Standard errors are clustered at the village level. The sample includes all respondents present at endline for whom we have the respective outcomes data, except for those in Free DFS households.

${ }^{3}$ Controls include the following variables from endline: Age, Age-Squared, a dummy for if the household split between baseline and endline, and a dummy for not present at baseline. The following baseline variables are also included: Completed 5th Standard or Higher, Body Mass Index (BMI), and Household Wealth Index. Note: For children under 10, education is for the head of the household.

${ }^{4}$ Regression also includes a dummy for if located in a non-sales village that received the movie treatment and a dummy for if located in a village that was eligible for the store incentive treatment, but did not receive it. 
Table 12: Balance Table for Those Observed at Endline

\begin{tabular}{|c|c|c|c|c|c|c|c|c|}
\hline & (1) & $(2)$ & (3) & (4) & $(5)$ & $(6)$ & (7) & (8) \\
\hline & $\begin{array}{l}\text { Control Mean } \\
\text { for Sales } \\
\text { Experiment }\end{array}$ & $\begin{array}{c}\text { Sales } \\
\text { Experiment } \\
\text { (No Free } \\
\text { DFS) }\end{array}$ & $\begin{array}{l}\text { P-value (Sales } \\
\text { Experiment) }\end{array}$ & $\begin{array}{l}\text { Observations } \\
\text { (Full Sample) }\end{array}$ & $\begin{array}{l}\text { Control Mean } \\
\text { for Free DFS } \\
\text { Experiment }\end{array}$ & $\begin{array}{c}\text { Free DFS } \\
\text { Experiment }\end{array}$ & $\begin{array}{c}\text { P-Value (Free } \\
\text { DFS) }\end{array}$ & $\begin{array}{c}\text { Observations } \\
\text { (Free DFS } \\
\text { Villages) }\end{array}$ \\
\hline \multicolumn{9}{|l|}{ Panel A: Individual-Level Variables } \\
\hline Age & $\begin{array}{c}28.117 \\
(20.116)\end{array}$ & $\begin{array}{c}27.803 \\
(20.085)\end{array}$ & 0.285 & 31755 & $\begin{array}{c}28.166 \\
(20.392)\end{array}$ & $\begin{array}{c}26.777 \\
(19.718)\end{array}$ & 0.005 & 5183 \\
\hline Elderly Individual (50+ years) & $\begin{array}{c}0.183 \\
(0.387)\end{array}$ & $\begin{array}{c}0.179 \\
(0.384)\end{array}$ & 0.456 & 32175 & $\begin{array}{c}0.189 \\
(0.391)\end{array}$ & $\begin{array}{c}0.160 \\
(0.367)\end{array}$ & 0.006 & 5239 \\
\hline Anemic & $\begin{array}{c}0.447 \\
(0.497)\end{array}$ & $\begin{array}{l}0.442 \\
(0.497)\end{array}$ & 0.713 & 28768 & $\begin{array}{c}0.455 \\
(0.498)\end{array}$ & $\begin{array}{c}0.454 \\
(0.498)\end{array}$ & 0.824 & 4635 \\
\hline Severe Anemia & $\begin{array}{c}0.007 \\
(0.082)\end{array}$ & $\begin{array}{c}0.008 \\
(0.086)\end{array}$ & 0.445 & 28768 & $\begin{array}{c}0.007 \\
(0.081)\end{array}$ & $\begin{array}{c}0.011 \\
(0.106)\end{array}$ & 0.145 & 4635 \\
\hline Hemoglobin Concentration & $\begin{array}{l}12.191 \\
(1.808)\end{array}$ & $\begin{array}{l}12.192 \\
(1.802)\end{array}$ & 0.940 & 28768 & $\begin{array}{l}12.172 \\
(1.808)\end{array}$ & $\begin{array}{l}12.084 \\
(1.876)\end{array}$ & 0.127 & 4635 \\
\hline Standardized Cognition Score & $\begin{array}{l}-0.008 \\
(0.991)\end{array}$ & $\begin{array}{l}-0.022 \\
(0.971)\end{array}$ & 0.560 & 26818 & $\begin{array}{c}0.004 \\
(0.968)\end{array}$ & $\begin{array}{l}-0.088 \\
(0.973)\end{array}$ & 0.005 & 4314 \\
\hline Standardized Mental Health Score & $\begin{array}{l}-0.006 \\
(0.997)\end{array}$ & $\begin{array}{l}-0.009 \\
(1.011)\end{array}$ & 0.913 & 21547 & $\begin{array}{l}-0.058 \\
(1.035)\end{array}$ & $\begin{array}{c}0.011 \\
(0.995)\end{array}$ & 0.250 & 3437 \\
\hline Standardized Physical Fitness Score & $\begin{array}{c}0.017 \\
(0.885)\end{array}$ & $\begin{array}{c}0.028 \\
(0.919)\end{array}$ & 0.692 & 12947 & $\begin{array}{l}-0.061 \\
(0.924)\end{array}$ & $\begin{array}{l}-0.046 \\
(0.955)\end{array}$ & 0.862 & 2020 \\
\hline Body Mass Index (BMI) & $\begin{array}{l}18.132 \\
(4.283)\end{array}$ & $\begin{array}{l}18.092 \\
(4.290)\end{array}$ & 0.628 & 29110 & $\begin{array}{l}18.228 \\
(4.435)\end{array}$ & $\begin{array}{l}17.917 \\
(4.690)\end{array}$ & 0.021 & 4684 \\
\hline & & & & & & & Continued on & next page... \\
\hline
\end{tabular}




\begin{tabular}{|c|c|c|c|c|c|c|c|c|}
\hline \multirow[t]{2}{*}{30 day Consumption per Capita } & 2340.194 & 2317.395 & 0.722 & 5678 & 2347.028 & 2350.476 & 0.978 & 891 \\
\hline & $(2906.224)$ & $(2408.160)$ & & & $(2853.984)$ & $(2656.458)$ & & \\
\hline \multirow[t]{2}{*}{ Household Head Completed $5+$ Years of Schooling } & 0.556 & 0.559 & 0.869 & 4993 & 0.565 & 0.486 & 0.014 & 785 \\
\hline & $(0.497)$ & $(0.497)$ & & & $(0.496)$ & $(0.500)$ & & \\
\hline \multirow[t]{2}{*}{ At least one elderly, anemic person in Household } & 0.490 & 0.472 & 0.256 & 5665 & 0.495 & 0.470 & 0.502 & 888 \\
\hline & $(0.500)$ & $(0.499)$ & & & $(0.501)$ & $(0.500)$ & & \\
\hline \multirow[t]{2}{*}{ Number of Household Members } & 6.603 & 6.738 & 0.213 & 5720 & 6.847 & 6.844 & 0.906 & 899 \\
\hline & $(3.485)$ & (3.927) & & & $(4.135)$ & (3.996) & & \\
\hline \multirow[t]{2}{*}{ Only Immediate Family Members in Household } & 0.350 & 0.355 & 0.728 & 5716 & 0.328 & 0.355 & 0.449 & 898 \\
\hline & $(0.477)$ & $(0.479)$ & & & $(0.470)$ & $(0.479)$ & & \\
\hline \multirow[t]{2}{*}{ Baseline Wealth Index } & -0.032 & -0.028 & 0.841 & 5718 & -0.006 & -0.010 & 0.949 & 898 \\
\hline & $(0.644)$ & $(0.601)$ & & & $(0.606)$ & $(0.772)$ & & \\
\hline \multirow[t]{2}{*}{ Household split since Baseline } & 0.152 & 0.166 & 0.236 & 5744 & 0.185 & 0.231 & 0.083 & 900 \\
\hline & $(0.359)$ & $(0.372)$ & & & $(0.389)$ & $(0.422)$ & & \\
\hline
\end{tabular}

1 The table presents summary statistics for only the people who we observed at endline (non-attritors). The sample used varies by column. Column 1 ("Control Mean for Sales Experiment") includes all respondents and households who were located in villages that did not receive the Sales intervention. Column 2 ("Sales Experiment (No Free DFS)") includes all those located in villages that were part of the Sales Experiment, excluding households that received the Free DFS Intervention. Column 5 ("Control Mean for Free DFS Experiment") includes all respondents who were in villages where the Free DFS treatment occurred, but in households that did not receive the Free DFS treatment. Column 6 ("Free DFS Experiment") includes those located in households that received the Free DFS Intervention.

2 The sample for "Individual-Level Variables" (except for "Individual in Baseline Sample") includes all baseline respondents from within the respective subsets (refer to footnotes 1) that we observe at endline. "Household-Level Variables" includes all households from baseline that we see at endline.

${ }^{3}$ Scores were standardized using the mean from the sales experiment control group at baseline. The cognition outcomes were standardized such that a positive score indicates a higher level of cognition. The physical fitness scores were standardized such that a positive score indicates being more physically fit. The score for the mental health outcomes were standardized such that a positive score indicates a higher level of depression.

${ }^{4}$ Standard deviations are in parentheses. 


\section{Online Appendix}

Table A1: Balance Checks (Baseline Respondents Only)

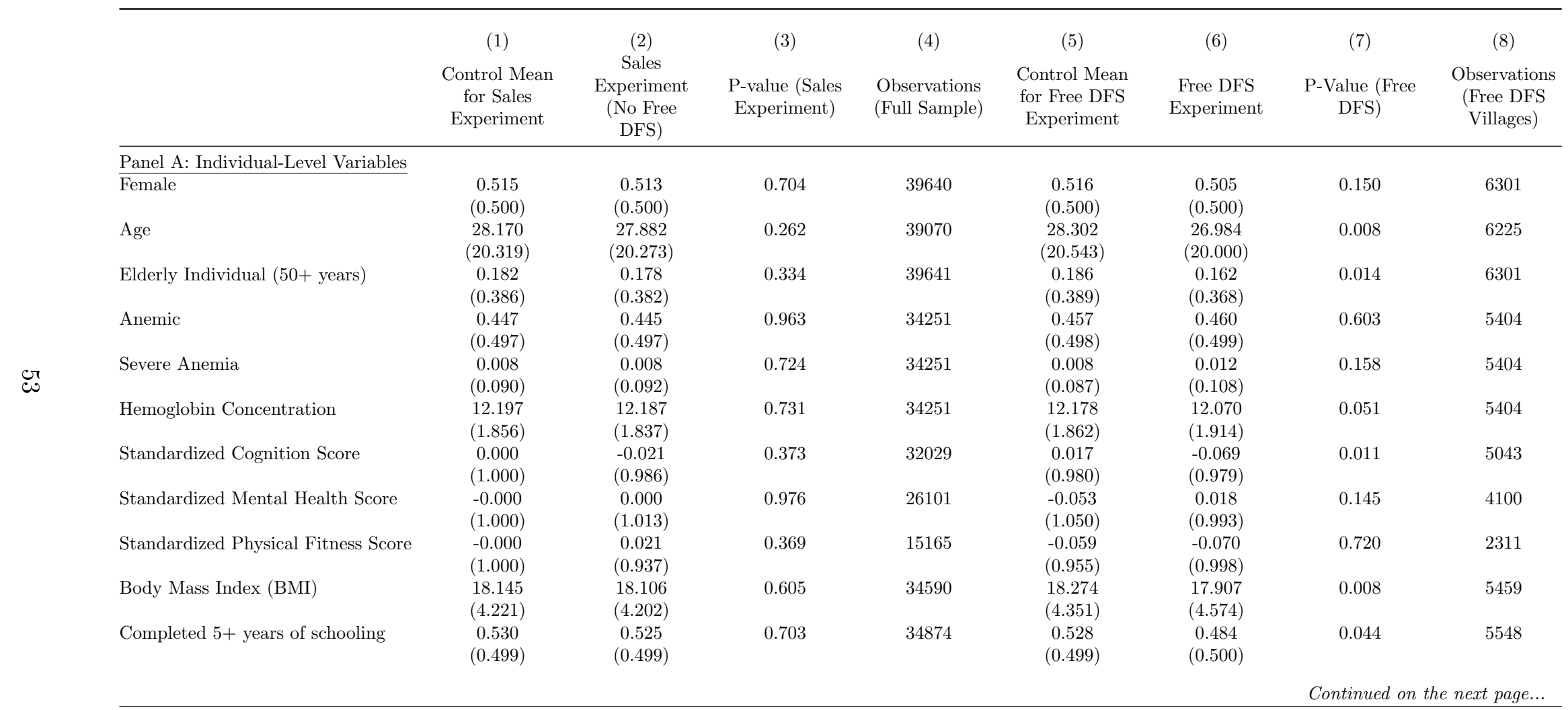


Panel B: Household-Level Variables

30 day Consumption per Capita

Household Head Completed 5+ Years of Schoolin

At least one elderly, anemic person in Household

Number of Household Members

Only Immediate Family Members in Household

Baseline Wealth Index

Household split since Baselin

Panel C: Attrition Measurements

Entire Household Lost to Attrition

Baseline Respondent Missing Endline Hemoglobin

Respondent Lost to Attrition since Baseline
Panel D: Take-Up Measurements

Currently Using DFS

Currently Using or Penultimately Used DFS

Tried DFS in the Past Yea

Times in Past Year Household Purchased DFS

\begin{tabular}{|c|c|c|c|c|c|c|c|}
\hline $\begin{array}{l}2351.154 \\
2897.359)\end{array}$ & $\begin{array}{c}2314.968 \\
(2395.552)\end{array}$ & 0.607 & 5953 & $\begin{array}{c}2326.878 \\
(2804.108)\end{array}$ & $\begin{array}{c}2338.572 \\
(2626.661)\end{array}$ & 0.938 & 923 \\
\hline $\begin{array}{l}0.555 \\
(0.497)\end{array}$ & $\begin{array}{c}0.558 \\
(0.497)\end{array}$ & 0.904 & 5001 & $\begin{array}{c}0.565 \\
(0.496)\end{array}$ & $\begin{array}{l}0.485 \\
(0.500)\end{array}$ & 0.012 & 786 \\
\hline $\begin{array}{c}0.488 \\
(0.500)\end{array}$ & $\begin{array}{c}0.468 \\
(0.499)\end{array}$ & 0.190 & 5906 & $\begin{array}{c}0.488 \\
(0.500)\end{array}$ & $\begin{array}{l}0.475 \\
(0.500)\end{array}$ & 0.708 & 917 \\
\hline $\begin{array}{c}(0.500) \\
6.542\end{array}$ & $\begin{array}{c}(0.499) \\
6.638\end{array}$ & 0.362 & 6003 & $\begin{array}{c}(0.500) \\
6.761\end{array}$ & $\begin{array}{c}(0.500) \\
6.760\end{array}$ & 0.949 & 932 \\
\hline (3.514) & (3.923) & & & $(4.125)$ & (3.988) & & \\
\hline $\begin{array}{c}0.356 \\
(0.479)\end{array}$ & $\begin{array}{c}0.367 \\
(0.482)\end{array}$ & 0.456 & 5996 & $\begin{array}{c}0.341 \\
(0.474)\end{array}$ & $\begin{array}{c}0.364 \\
(0.482)\end{array}$ & 0.460 & 930 \\
\hline-0.037 & -0.040 & 0.892 & 6001 & -0.018 & -0.016 & 0.996 & 931 \\
\hline (0.653) & $(0.625)$ & & & (0.637) & $(0.765)$ & & \\
\hline 0.146 & 0.157 & 0.322 & 6004 & 0.177 & 0.226 & 0.054 & 932 \\
\hline$(0.353)$ & $(0.364)$ & & & $(0.382)$ & $(0.419)$ & & \\
\hline 0.039 & 0.052 & 0.043 & 6004 & 0.044 & 0.023 & 0.065 & 932 \\
\hline (0.194) & $(0.222)$ & & & $(0.206)$ & $(0.150)$ & & \\
\hline 0.215 & 0.217 & 0.905 & 39646 & 0.211 & 0.166 & 0.003 & 6302 \\
\hline (0.411) & $(0.412)$ & & & (0.408) & $(0.372)$ & & \\
\hline $\begin{array}{c}0.192 \\
(0.394)\end{array}$ & $\begin{array}{c}0.191 \\
(0.393)\end{array}$ & 0.889 & 39646 & $\begin{array}{c}0.185 \\
(0.388)\end{array}$ & $\begin{array}{c}0.150 \\
(0.357)\end{array}$ & 0.018 & 6302 \\
\hline $\begin{array}{c}0.034 \\
(0.182)\end{array}$ & $\begin{array}{c}0.145 \\
(0.353)\end{array}$ & 0.000 & 6247 & $\begin{array}{c}0.157 \\
(0.364)\end{array}$ & $\begin{array}{c}0.614 \\
(0.487)\end{array}$ & 0.000 & 1054 \\
\hline 0.046 & $\begin{array}{l}0.219 \\
(0.414)\end{array}$ & 0.000 & 4062 & $\begin{array}{l}0.232 \\
(0.423)\end{array}$ & $\begin{array}{l}0.760 \\
(0.428)\end{array}$ & 0.000 & 716 \\
\hline $\begin{array}{c}(0.210) \\
0.108\end{array}$ & $\begin{array}{c}(0.414) \\
0.426\end{array}$ & 0.000 & 4400 & $\begin{array}{c}(0.423) \\
0.423\end{array}$ & $\begin{array}{c}(0.420) \\
0.746\end{array}$ & 0.000 & 780 \\
\hline$(0.310)$ & $(0.495)$ & & & $(0.495)$ & $(0.436)$ & & \\
\hline 0.781 & 3.323 & 0.000 & 4400 & 3.682 & 6.706 & 0.000 & 780 \\
\hline$(4.013)$ & (7.107) & & & (7.878) & (7.409) & & \\
\hline
\end{tabular}

The table presents summary statistics for all those in our sample for whom we have the respective data. The sample used varies by column. Column 1 ("Control Mean for Sales Experiment") includes all respondents and households who were located in villages that did not receive the Sales intervention. Column 2 ("Sales Experiment (No Free DFS)") includes all those located in villages that were part of the Sales Experiment, excluding households that received the Free DFS Intervention. Column 5 ("Control Mean for Free DFS Experiment") includes all respondents who were in villages where the Free DFS treatment occurred, but in households that did not receive the Free DFS treatment. Column 6 ("Free DFS Experiment") includes those located in households that received the Free DFS Intervention.

${ }^{2}$ The sample for "Individual-Level Variables" (except for "Individual in Baseline Sample") includes all baseline respondents from within the respective subsets (refer to footnote 1) that we observe at endline. "Household-Level Variables" includes all households from baseline that we see at endline.

${ }^{3}$ Scores were standardized using the mean from the sales experiment control group at baseline. The cognition outcomes were standardized such that a positive score indicates a higher level of cognition. The physical fitness scores were standardized such that a positive score indicates being more physically fit. The score for the mental health outcomes were standardized such that a positive score indicates a lower level of depression.

${ }^{4}$ Standard deviations are in parentheses. 
Table A2: Sales Experiment - Hemoglobin \& Anemia by Gender and Age (Baseline Respondents Only)

\begin{tabular}{|c|c|c|c|c|c|c|}
\hline Sample: & $\begin{array}{l}(1) \\
\text { All }\end{array}$ & $\begin{array}{c}(2) \\
\text { Female }\end{array}$ & $\begin{array}{l}(3) \\
\text { Male }\end{array}$ & $\begin{array}{c}(4) \\
\text { Child }(<15 \text { years })\end{array}$ & $\begin{array}{c}(5) \\
\text { Adult (15-49 years) }\end{array}$ & $\begin{array}{c}(6) \\
\text { Elderly }(50+\text { years })\end{array}$ \\
\hline \multicolumn{7}{|c|}{ Panel A: Hemoglobin Concentration } \\
\hline Sales village & $\begin{array}{c}0.045 \\
{[0.029]}\end{array}$ & $\begin{array}{c}0.015 \\
{[0.030]}\end{array}$ & $\begin{array}{c}0.072 \\
{[0.035]}\end{array}$ & $\begin{array}{c}0.058 \\
{[0.035]}\end{array}$ & $\begin{array}{c}0.055 \\
{[0.038]}\end{array}$ & $\begin{array}{l}-0.004 \\
{[0.046]}\end{array}$ \\
\hline Q-value & & $(0.459)$ & $(0.087)$ & $(0.411)$ & $(0.411)$ & $(0.856)$ \\
\hline Control Mean & 12.163 & 11.497 & 12.891 & 11.725 & 12.578 & 11.977 \\
\hline \multicolumn{7}{|c|}{ Panel B: Anemia } \\
\hline Sales village & $\begin{array}{l}-0.004 \\
{[0.009]}\end{array}$ & $\begin{array}{c}0.003 \\
{[0.011]}\end{array}$ & $\begin{array}{l}-0.010 \\
{[0.010]}\end{array}$ & $\begin{array}{l}-0.012 \\
{[0.013]}\end{array}$ & $\begin{array}{l}-0.007 \\
{[0.010]}\end{array}$ & $\begin{array}{c}0.017 \\
{[0.012]}\end{array}$ \\
\hline Q-value & & $(1.000)$ & $(1.000)$ & $(1.000)$ & $(1.000)$ & $(1.000)$ \\
\hline Control Mean & 0.476 & 0.584 & 0.358 & 0.425 & 0.456 & 0.604 \\
\hline Observations & 28780 & 14946 & 13769 & 9770 & 13065 & 5870 \\
\hline \multicolumn{7}{|c|}{ Panel C: Hemoglobin Concentration (Baseline Anemic Only) } \\
\hline Sales village & $\begin{array}{c}0.077 \\
{[0.040]}\end{array}$ & $\begin{array}{c}0.045 \\
{[0.042]}\end{array}$ & $\begin{array}{c}0.145 \\
{[0.055]}\end{array}$ & $\begin{array}{c}0.134 \\
{[0.054]}\end{array}$ & $\begin{array}{c}0.062 \\
{[0.054]}\end{array}$ & $\begin{array}{c}0.048 \\
{[0.064]}\end{array}$ \\
\hline Q-value & & $(0.166)$ & $(0.018)$ & $(0.054)$ & $(0.302)$ & $(0.302)$ \\
\hline Control Mean & 11.364 & 11.027 & 11.917 & 11.248 & 11.544 & 11.205 \\
\hline \multicolumn{7}{|c|}{ Panel D: Anemia (Baseline Anemic Only) } \\
\hline Sales village & $\begin{array}{l}-0.015 \\
{[0.011]}\end{array}$ & $\begin{array}{l}-0.004 \\
{[0.013]}\end{array}$ & $\begin{array}{l}-0.035 \\
{[0.015]}\end{array}$ & $\begin{array}{l}-0.026 \\
{[0.020]}\end{array}$ & $\begin{array}{l}-0.014 \\
{[0.014]}\end{array}$ & $\begin{array}{l}-0.009 \\
{[0.015]}\end{array}$ \\
\hline Q-value & & $(0.643)$ & $(0.048)$ & $(1.000)$ & $(1.000)$ & $(1.000)$ \\
\hline Control Mean & 0.669 & 0.722 & 0.581 & 0.561 & 0.674 & 0.785 \\
\hline Observations & 11505 & 7167 & 4318 & 3535 & 4909 & 3035 \\
\hline
\end{tabular}

\footnotetext{
${ }^{1}$ Standard errors in brackets.
}

${ }^{2}$ Regression includes block-fixed effects. Standard errors are clustered at the village level. The sample includes all respondents present at endline for whom we have the respective outcomes data, excluding Free DFS Households.

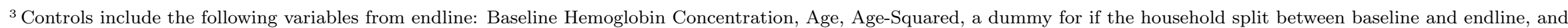

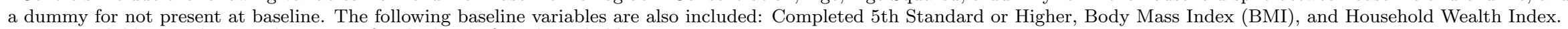
Note: For children under 10, education is for the head of the household.

${ }^{4}$ Anemia thresholds are determined by age and gender, therefore, a dummy for each of these age groups is included in the regressions for anemia. 
Table A3: Free DFS Experiment Compared to Control - Hemoglobin \& Anemia by Gender and Age (Baseline Respondents Only)

\begin{tabular}{|c|c|c|c|c|c|c|}
\hline Sample: & $\begin{array}{l}(1) \\
\text { All }\end{array}$ & $\begin{array}{c}(2) \\
\text { Female }\end{array}$ & $\begin{array}{l}\text { (3) } \\
\text { Male }\end{array}$ & $\begin{array}{c}(4) \\
\text { Child }(<15 \text { years })\end{array}$ & $\begin{array}{c}(5) \\
\text { Adult (15-49 years) }\end{array}$ & $\begin{array}{c}(6) \\
\text { Elderly }(50+\text { years })\end{array}$ \\
\hline \multicolumn{7}{|l|}{ Panel A: Hemoglobin Concentration } \\
\hline$\overline{\text { Household in Free DFS Treatment }}$ & $\begin{array}{c}0.038 \\
{[0.051]}\end{array}$ & $\begin{array}{c}0.025 \\
{[0.056]}\end{array}$ & $\begin{array}{c}0.011 \\
{[0.061]}\end{array}$ & $\begin{array}{c}0.108 \\
{[0.058]}\end{array}$ & $\begin{array}{c}0.044 \\
{[0.062]}\end{array}$ & $\begin{array}{l}-0.152 \\
{[0.083]}\end{array}$ \\
\hline Control Mean & 12.163 & 11.497 & 12.891 & 11.725 & 12.578 & 11.977 \\
\hline \multicolumn{7}{|l|}{ Panel B. Anemia } \\
\hline Household in Free DFS Treatment & $\begin{array}{l}-0.014 \\
{[0.016]}\end{array}$ & $\begin{array}{l}-0.011 \\
{[0.019]}\end{array}$ & $\begin{array}{l}-0.011 \\
{[0.019]}\end{array}$ & $\begin{array}{l}-0.031 \\
{[0.021]}\end{array}$ & $\begin{array}{l}-0.009 \\
{[0.018]}\end{array}$ & $\begin{array}{c}0.008 \\
{[0.025]}\end{array}$ \\
\hline Control Mean & 0.476 & 0.584 & 0.358 & 0.425 & 0.456 & 0.604 \\
\hline Observations & 17861 & 9285 & 8528 & 6089 & 8076 & 3633 \\
\hline \multicolumn{7}{|c|}{ Panel C: Hemoglobin Concentration (Baseline Anemic Only) } \\
\hline Household in Free DFS Treatment & $\begin{array}{c}0.018 \\
{[0.072]}\end{array}$ & $\begin{array}{c}0.086 \\
{[0.075]}\end{array}$ & $\begin{array}{l}-0.119 \\
{[0.100]}\end{array}$ & $\begin{array}{c}0.079 \\
{[0.096]}\end{array}$ & $\begin{array}{c}0.059 \\
{[0.094]}\end{array}$ & $\begin{array}{l}-0.159 \\
{[0.108]}\end{array}$ \\
\hline Q-value & & $(0.340)$ & $(0.340)$ & $(1.000)$ & $(1.000)$ & $(1.000)$ \\
\hline Control Mean & 11.364 & 11.027 & 11.917 & 11.248 & 11.544 & 11.205 \\
\hline \multicolumn{7}{|c|}{ Panel D: Anemia (Baseline Anemic Only) } \\
\hline Q-value & & $(0.942)$ & $(0.942)$ & $(1.000)$ & $(1.000)$ & $(1.000)$ \\
\hline Control Mean & 0.669 & 0.722 & 0.581 & 0.561 & 0.674 & 0.785 \\
\hline Observations & 7192 & 4461 & 2717 & 2202 & 3043 & 1913 \\
\hline
\end{tabular}

${ }^{1}$ Standard errors in brackets.

${ }^{2}$ Standard errors are cluster at the village level. The sample includes all respondents located in the Sales Experiment control group or Free DFS households, who were present at endline and for whom we have the respective outcomes data.

${ }^{3}$ Controls include the following variables from endline: Baseline Hemoglobin Concentration, Age, Age-Squared, a dummy for if the household split between baseline and endline, and

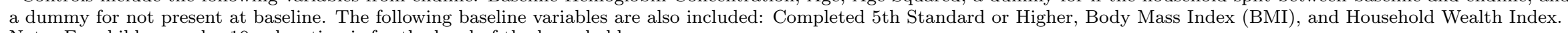
Note: For children under 10, education is for the head of the household.

${ }^{4}$ Anemia thresholds are determined by age and gender, therefore, a dummy for each of these age groups is included in the regressions for anemia. 
Table A4: Free DFS Experiment in Free DFS Villages - Hemoglobin \& Anemia by Gender and Age (Baseline Respondents Only)

\begin{tabular}{|c|c|c|c|c|c|c|}
\hline Sample: & $\begin{array}{l}(1) \\
\text { All }\end{array}$ & $\begin{array}{c}(2) \\
\text { Female }\end{array}$ & $\begin{array}{l}(3) \\
\text { Male }\end{array}$ & $\begin{array}{c}(4) \\
\text { Child }(<15 \text { years })\end{array}$ & $\begin{array}{c}(5) \\
\text { Adult }(15-49 \text { years })\end{array}$ & $\begin{array}{ll}(6) & \\
\text { Elderly }(50+\text { years })\end{array}$ \\
\hline$\frac{\text { Panel A: Hemoglobin Concentration }}{\text { Household in Free DFS Treatment }}$ & $\begin{array}{l}-0.001 \\
{[0.046]}\end{array}$ & $\begin{array}{c}0.009 \\
{[0.054]}\end{array}$ & $\begin{array}{l}-0.054 \\
{[0.062]}\end{array}$ & $\begin{array}{c}0.033 \\
{[0.059]}\end{array}$ & $\begin{array}{c}0.029 \\
{[0.066]}\end{array}$ & $\begin{array}{l}-0.155 \\
{[0.105]}\end{array}$ \\
\hline $\begin{array}{l}\text { Panel B: Anemia } \\
\text { Household in Free DFS Treatment }\end{array}$ & $\begin{array}{l}-0.009 \\
{[0.015]}\end{array}$ & $\begin{array}{l}-0.013 \\
{[0.020]}\end{array}$ & $\begin{array}{l}-0.006 \\
{[0.018]}\end{array}$ & $\begin{array}{l}-0.025 \\
{[0.025]}\end{array}$ & $\begin{array}{l}-0.008 \\
{[0.019]}\end{array}$ & $\begin{array}{l}-0.001 \\
{[0.029]}\end{array}$ \\
\hline $\begin{array}{l}\text { Panel C: Hemoglobin Concentration } \\
\text { Household in Free DFS Treatment }\end{array}$ & $\begin{array}{c}0.011 \\
{[0.072]}\end{array}$ & $\begin{array}{c}0.094 \\
{[0.080]}\end{array}$ & $\begin{array}{l}-0.179 \\
{[0.127]}\end{array}$ & $\begin{array}{l}-0.035 \\
{[0.100]}\end{array}$ & $\begin{array}{c}0.072 \\
{[0.110]}\end{array}$ & $\begin{array}{l}-0.109 \\
{[0.158]}\end{array}$ \\
\hline $\begin{array}{l}\text { Q-value } \\
\text { Control Mean }\end{array}$ & 11.413 & $\begin{array}{l}(0.313) \\
11.030\end{array}$ & $\begin{array}{l}(0.313) \\
12.087\end{array}$ & $\begin{array}{l}(1.000) \\
11.466\end{array}$ & $\begin{array}{l}(1.000) \\
11.528\end{array}$ & $\begin{array}{l}(1.000) \\
11.165\end{array}$ \\
\hline $\begin{array}{l}\text { Panel D: Anemia (Baseline Anemic } \\
\text { Household in Free DFS Treatment }\end{array}$ & $\begin{array}{l}-0.005 \\
{[0.022]}\end{array}$ & $\begin{array}{l}-0.032 \\
{[0.026]}\end{array}$ & $\begin{array}{c}0.018 \\
{[0.037]}\end{array}$ & $\begin{array}{l}-0.004 \\
{[0.041]}\end{array}$ & $\begin{array}{l}-0.027 \\
{[0.032]}\end{array}$ & $\begin{array}{l}-0.006 \\
{[0.035]}\end{array}$ \\
\hline $\begin{array}{l}\text { Q-value } \\
\text { Control Mean } \\
\text { Observations }\end{array}$ & $\begin{array}{l}0.663 \\
2059\end{array}$ & $\begin{array}{c}(0.739) \\
0.734 \\
1290\end{array}$ & $\begin{array}{c}(0.739) \\
0.542 \\
763\end{array}$ & $\begin{array}{c}(1.000) \\
0.523 \\
659\end{array}$ & $\begin{array}{c}(1.000) \\
0.698 \\
867\end{array}$ & $\begin{array}{c}(1.000) \\
0.773 \\
524\end{array}$ \\
\hline
\end{tabular}

Standard errors in brackets.

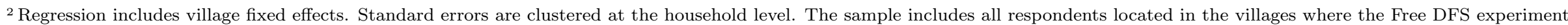
took place, who were present at endline and for whom we have the respective outcomes data.

${ }^{3}$ Controls include the following variables from endline: Baseline Hemoglobin Concentration, Age, Age-Squared, a dummy for if the household split between baseline and endline, and

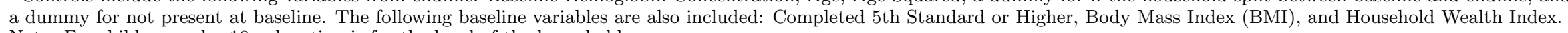
Note: For children under 10, education is for the head of the household.

${ }^{4}$ Anemia thresholds are determined by age and gender, therefore, a dummy for each of these age groups is included in the regressions for anemia. 
Table A5: First Stage for Salt Consumption - Currently Using or Penultimately Used DFS (Baseline Respondents Only)

\begin{tabular}{|c|c|c|c|c|c|c|}
\hline Sample: & $\begin{array}{l}(1) \\
\text { All }\end{array}$ & $\begin{array}{c}(2) \\
\text { Female }\end{array}$ & $\begin{array}{l}(3) \\
\text { Male }\end{array}$ & $\begin{array}{c}(4) \\
\text { All Anemic } \\
2\end{array}$ & $\begin{array}{c}(5) \\
\text { Anemic Female }{ }^{2}\end{array}$ & $\begin{array}{c}(6) \\
\text { Anemic Male }^{2}\end{array}$ \\
\hline Sales village & $\begin{array}{c}0.170 \\
{[0.020]}\end{array}$ & $\begin{array}{c}0.173 \\
{[0.020]}\end{array}$ & $\begin{array}{c}0.166 \\
{[0.020]}\end{array}$ & $\begin{array}{c}0.165 \\
{[0.021]}\end{array}$ & $\begin{array}{c}0.162 \\
{[0.022]}\end{array}$ & $\begin{array}{c}0.171 \\
{[0.023]}\end{array}$ \\
\hline Household in Free DFS Treatment & $\begin{array}{c}0.510 \\
{[0.045]}\end{array}$ & $\begin{array}{c}0.483 \\
{[0.049]}\end{array}$ & $\begin{array}{c}0.538 \\
{[0.042]}\end{array}$ & $\begin{array}{c}0.523 \\
{[0.049]}\end{array}$ & $\begin{array}{c}0.504 \\
{[0.053]}\end{array}$ & $\begin{array}{c}0.552 \\
{[0.047]}\end{array}$ \\
\hline $\begin{array}{l}\text { P-value: Sales Experiment } \\
\text { Free DFS Household }=0\end{array}$ & 0.000 & 0.000 & 0.000 & 0.000 & 0.000 & 0.000 \\
\hline Control Mean & 0.049 & 0.049 & 0.049 & 0.047 & 0.050 & 0.042 \\
\hline Observations & 22429 & 11506 & 10878 & 8925 & 5536 & 3374 \\
\hline
\end{tabular}

${ }^{1}$ Standard errors in brackets.

2 The Anemic Female and Anemic Male groups refer to females and males (respectively) who were anemic at baseline. All anemic includes both males and females who were anemic at baseline.

${ }^{3}$ Standard errors are clustered at the village level and the regression includes all respondents who were present at endline and for whom we have the respective outcomes data.

${ }^{4}$ Controls include the following variables from endline: Age, Age-Squared, a dummy for if the household split between baseline and endline, and a dummy for not present at baseline. The following baseline variables are also included: Baseline Hemoglobin Concentration, Completed 5th Standard or Higher, Body Mass Index (BMI), and Household Wealth Index. Note: For children under 10, education is for the head of the household. 
Table A6: All Health Outcomes - 2SLS Estimates (Baseline Respondents Only)

\begin{tabular}{|c|c|c|c|c|c|c|}
\hline Sample: & $\begin{array}{l}(1) \\
\text { All }\end{array}$ & $\begin{array}{c}(2) \\
\text { Female }\end{array}$ & $\begin{array}{c}(3) \\
\text { Male }\end{array}$ & $\begin{array}{c}(4) \\
\text { All Anemic } \\
\end{array}$ & $\begin{array}{c}(5) \\
\text { Anemic Female }^{2} \\
\end{array}$ & $\begin{array}{c}(6) \\
\text { Anemic } \text { Male }^{2}\end{array}$ \\
\hline \multicolumn{7}{|l|}{ Panel A: Hemoglobin Concentration } \\
\hline Currently Using or Penultimately Used DFS & $\begin{array}{c}0.035 \\
{[0.092]}\end{array}$ & $\begin{array}{l}-0.006 \\
{[0.100]}\end{array}$ & $\begin{array}{c}0.010 \\
{[0.109]}\end{array}$ & $\begin{array}{c}0.020 \\
{[0.126]}\end{array}$ & $\begin{array}{c}0.122 \\
{[0.138]}\end{array}$ & $\begin{array}{l}-0.113 \\
{[0.164]}\end{array}$ \\
\hline Control Mean & 12.163 & 11.497 & 12.891 & 11.364 & 11.027 & 11.917 \\
\hline \multicolumn{7}{|l|}{ Panel B: Anemia } \\
\hline Currently Using or Penultimately Used DFS & $\begin{array}{l}-0.008 \\
{[0.030]}\end{array}$ & $\begin{array}{c}0.010 \\
{[0.036]}\end{array}$ & $\begin{array}{l}-0.015 \\
{[0.033]}\end{array}$ & $\begin{array}{l}-0.008 \\
{[0.040]}\end{array}$ & $\begin{array}{l}-0.007 \\
{[0.045]}\end{array}$ & $\begin{array}{l}-0.008 \\
{[0.049]}\end{array}$ \\
\hline Observations & 18889 & 9881 & 8969 & 7731 & 4840 & 2876 \\
\hline \multicolumn{7}{|l|}{ Panel C: Standardized Cognition Score } \\
\hline$\overline{\text { Currently Using or Penultimately Used DFS }}$ & $\begin{array}{l}-0.065 \\
{[0.059]}\end{array}$ & $\begin{array}{l}-0.064 \\
{[0.077]}\end{array}$ & $\begin{array}{l}-0.095 \\
{[0.067]}\end{array}$ & $\begin{array}{l}-0.105 \\
{[0.077]}\end{array}$ & $\begin{array}{l}-0.145 \\
{[0.089]}\end{array}$ & $\begin{array}{l}-0.061 \\
{[0.108]}\end{array}$ \\
\hline Control Mean & 0.005 & -0.275 & 0.297 & -0.115 & -0.358 & 0.274 \\
\hline Observations & 15865 & 8162 & 7669 & 6302 & 3926 & 2364 \\
\hline \multicolumn{7}{|l|}{ Panel D: Standardized Physical Fitness Score } \\
\hline$\overline{\text { Currently Using or Penultimately Used DFS }}$ & $\begin{array}{l}-0.085 \\
{[0.105]}\end{array}$ & $\begin{array}{l}-0.148 \\
{[0.119]}\end{array}$ & $\begin{array}{l}-0.006 \\
{[0.107]}\end{array}$ & $\begin{array}{l}-0.079 \\
{[0.126]}\end{array}$ & $\begin{array}{l}-0.113 \\
{[0.140]}\end{array}$ & $\begin{array}{l}-0.001 \\
{[0.177]}\end{array}$ \\
\hline Control Mean & -0.435 & -0.555 & -0.264 & -0.487 & -0.558 & -0.330 \\
\hline Observations & 8871 & 5260 & 3604 & 3630 & 2584 & 1043 \\
\hline \multicolumn{7}{|l|}{ Panel E: Standardized Mental Health Score } \\
\hline Currently Using or Penultimately Used DFS & $\begin{array}{c}-0.048 \\
{[0.076]}\end{array}$ & $\begin{array}{c}0.004 \\
{[0.102]}\end{array}$ & $\begin{array}{l}-0.117 \\
{[0.074]}\end{array}$ & $\begin{array}{l}-0.028 \\
{[0.100]}\end{array}$ & $\begin{array}{l}-0.020 \\
{[0.119]}\end{array}$ & $\begin{array}{c}-0.026 \\
{[0.112]}\end{array}$ \\
\hline Control Mean & -0.099 & -0.330 & 0.170 & -0.194 & -0.361 & 0.123 \\
\hline Observations & 15224 & 8198 & 7009 & 6164 & 4096 & 2061 \\
\hline
\end{tabular}

1 Standard errors in brackets.

${ }^{2}$ The Anemic Female and Anemic Male groups refer to females and males (respectively) who were anemic at baseline. All anemic includes both males and females who were anemic at baseline.

${ }^{3}$ Standard errors are clustered at the village level and the regression includes all respondents who were present at endline and for whom we have the respective outcomes data. Currently using DFS or Penultimately Used DFS is instrumented by a dummy for Sales Experiment and a dummy for Free DFS Households.

${ }^{4}$ Controls include the following variables from endline: Age, Age-Squared, a dummy for if the household split between baseline and endline, and a dummy for not present at baseline. The following baseline variables are also included: Baseline Hemoglobin Concentration, Completed 5th Standard or Higher, Body Mass Index (BMI), and Household Wealth Index. Note: For children under 10, education is for the head of the household.

${ }^{5}$ Scores were standardized using the mean from the sales experiment control group at baseline. The cognition outcomes were standardized such that a positive score indicates a higher level of cognition. The physical fitness scores were standardized such that a positive score indicates being more physically fit. The score for the mental health outcomes were standardized such that a positive score indicates a lower level of depression.

${ }^{6}$ Anemia thresholds are determined by age and gender, therefore, a dummy for each of these age groups is included in the regressions for anemia. 
Table A7a: Health Outcomes - Standardized Cognition Scores (Baseline Respondents Only)

\begin{tabular}{|c|c|c|c|c|c|c|}
\hline Sample: & $\begin{array}{l}(1) \\
\text { All }\end{array}$ & $\begin{array}{c}(2) \\
\text { Female }\end{array}$ & $\begin{array}{l}(3) \\
\text { Male }\end{array}$ & $\begin{array}{c}(4) \\
\text { Child }(<15 \text { years })\end{array}$ & $\begin{array}{c}(5) \\
\text { Adult (15-49 years) }\end{array}$ & $\begin{array}{l}(6) \\
\text { Elderly }(50+\text { years })\end{array}$ \\
\hline \multicolumn{7}{|l|}{ Panel A: Sales Experiment } \\
\hline$\overline{\text { Sales village }}$ & $\begin{array}{c}0.000 \\
{[0.022]}\end{array}$ & $\begin{array}{c}0.000 \\
{[0.026]}\end{array}$ & $\begin{array}{l}-0.004 \\
{[0.023]}\end{array}$ & $\begin{array}{c}0.019 \\
{[0.028]}\end{array}$ & $\begin{array}{c}0.005 \\
{[0.022]}\end{array}$ & $\begin{array}{l}-0.003 \\
{[0.036]}\end{array}$ \\
\hline Q-value & $(1.000)$ & $(1.000)$ & $(0.470)$ & $(0.514)$ & $(1.000)$ & $(1.000)$ \\
\hline Control Mean & 0.005 & -0.275 & 0.297 & 0.319 & -0.438 & 0.525 \\
\hline Observations & 26194 & 13351 & 12781 & 8574 & 12254 & 5307 \\
\hline \multicolumn{7}{|c|}{ Panel B: Sales Experiment (Baseline Anemic Only) } \\
\hline Sales village & $\begin{array}{c}0.014 \\
{[0.028]}\end{array}$ & $\begin{array}{c}0.001 \\
{[0.031]}\end{array}$ & $\begin{array}{c}0.028 \\
{[0.036]}\end{array}$ & $\begin{array}{c}0.024 \\
{[0.039]}\end{array}$ & $\begin{array}{l}-0.001 \\
{[0.025]}\end{array}$ & $\begin{array}{l}-0.014 \\
{[0.047]}\end{array}$ \\
\hline Q-value & $(1.000)$ & $(1.000)$ & $(1.000)$ & $(1.000)$ & $(1.000)$ & $(1.000)$ \\
\hline Control Mean & -0.115 & -0.358 & 0.274 & 0.106 & -0.549 & 0.377 \\
\hline Observations & 10240 & 6318 & 3902 & 2976 & 4550 & 2689 \\
\hline \multicolumn{7}{|l|}{ Panel C: Free DFS Households } \\
\hline Household in Free DFS Treatment & $\begin{array}{l}-0.061 \\
{[0.034]}\end{array}$ & $\begin{array}{l}-0.052 \\
{[0.040]}\end{array}$ & $\begin{array}{l}-0.089 \\
{[0.038]}\end{array}$ & $\begin{array}{c}0.040 \\
{[0.043]}\end{array}$ & $\begin{array}{l}-0.049 \\
{[0.034]}\end{array}$ & $\begin{array}{l}-0.163 \\
{[0.072]}\end{array}$ \\
\hline Q-value & $(0.234)$ & $(0.320)$ & $(0.066)$ & $(0.548)$ & $(0.512)$ & $(0.082)$ \\
\hline Control Mean & 0.005 & -0.275 & 0.297 & 0.319 & -0.438 & 0.525 \\
\hline \multicolumn{7}{|c|}{ Panel D: Free DFS Households (Baseline Anemic Only) } \\
\hline Household in Free DFS Treatment & $\begin{array}{l}-0.073 \\
{[0.046]}\end{array}$ & $\begin{array}{l}-0.089 \\
{[0.048]}\end{array}$ & $\begin{array}{l}-0.074 \\
{[0.071]}\end{array}$ & $\begin{array}{c}0.057 \\
{[0.067]}\end{array}$ & $\begin{array}{l}-0.065 \\
{[0.045]}\end{array}$ & $\begin{array}{l}-0.229 \\
{[0.087]}\end{array}$ \\
\hline Q-value & $(0.538)$ & $(0.256)$ & (1.000) & (1.000) & $(0.204)$ & $(0.030)$ \\
\hline Control Mean & -0.115 & -0.358 & 0.274 & 0.106 & -0.549 & 0.377 \\
\hline Observations & 5873 & 3622 & 2239 & 1679 & 2623 & 1547 \\
\hline
\end{tabular}

1 Standard errors in brackets.

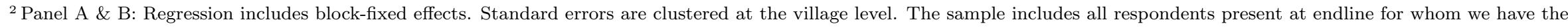
respective outcomes data, excluding Free DFS Households. Panel C \& D: Standard errors are cluster at the village level. The sample includes all respondents located in the Sales Experiment control group or Free DFS households, who were present at endline and for whom we have the respective outcomes data.

${ }^{3}$ Controls include the following variables from endline: Baseline Hemoglobin Concentration, Age, Age-Squared, a dummy for if the household split between baseline and endline, and

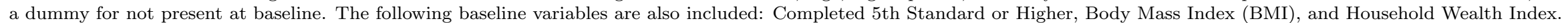
Note: For children under 10, education is for the head of the household. 
Table A7b: Health Outcomes - Standardized Physical Fitness (Baseline Respondents Only)

\begin{tabular}{|c|c|c|c|c|c|c|}
\hline Sample: & $\begin{array}{l}(1) \\
\text { All }\end{array}$ & $\begin{array}{c}(2) \\
\text { Female }\end{array}$ & $\begin{array}{l}(3) \\
\text { Male }\end{array}$ & $\begin{array}{c}(4) \\
\text { Child }(<15 \text { years })\end{array}$ & $\begin{array}{c}(5) \\
\text { Adult (15-49 years) }\end{array}$ & $\begin{array}{l}(6) \\
\text { Elderly }(50+\text { years })\end{array}$ \\
\hline \multicolumn{7}{|l|}{ Panel A: Sales Experiment } \\
\hline$\overline{\text { Sales village }}$ & $\begin{array}{l}-0.016 \\
{[0.034]}\end{array}$ & $\begin{array}{l}-0.002 \\
{[0.039]}\end{array}$ & $\begin{array}{l}-0.050 \\
{[0.040]}\end{array}$ & $\begin{array}{l}-0.046 \\
{[0.054]}\end{array}$ & $\begin{array}{c}0.008 \\
{[0.040]}\end{array}$ & $\begin{array}{l}-0.058 \\
{[0.046]}\end{array}$ \\
\hline Q-value & $(1.000)$ & $(1.000)$ & $(0.470)$ & $(0.514)$ & $(1.000)$ & $(1.000)$ \\
\hline Control Mean & -0.435 & -0.555 & -0.264 & -0.330 & -0.410 & -0.564 \\
\hline Observations & 14824 & 8661 & 6148 & 2449 & 8847 & 3528 \\
\hline \multicolumn{7}{|c|}{ Panel B: Sales Experiment (Baseline Anemic Only) } \\
\hline Sales village & $\begin{array}{l}-0.033 \\
{[0.038]}\end{array}$ & $\begin{array}{l}-0.027 \\
{[0.042]}\end{array}$ & $\begin{array}{l}-0.058 \\
{[0.055]}\end{array}$ & $\begin{array}{l}-0.057 \\
{[0.085]}\end{array}$ & $\begin{array}{l}-0.021 \\
{[0.044]}\end{array}$ & $\begin{array}{l}-0.056 \\
{[0.058]}\end{array}$ \\
\hline Q-value & $(1.000)$ & $(1.000)$ & $(1.000)$ & $(1.000)$ & $(1.000)$ & $(1.000)$ \\
\hline Control Mean & -0.487 & -0.558 & -0.330 & -0.337 & -0.433 & -0.661 \\
\hline Observations & 6016 & 4196 & 1813 & 818 & 3509 & 1689 \\
\hline \multicolumn{7}{|l|}{ Panel C: Free DFS Households } \\
\hline Household in Free DFS Treatment & $\begin{array}{l}-0.096 \\
{[0.062]}\end{array}$ & $\begin{array}{l}-0.121 \\
{[0.069]}\end{array}$ & $\begin{array}{l}-0.075 \\
{[0.070]}\end{array}$ & $\begin{array}{l}-0.220 \\
{[0.095]}\end{array}$ & $\begin{array}{l}-0.081 \\
{[0.067]}\end{array}$ & $\begin{array}{l}-0.022 \\
{[0.089]}\end{array}$ \\
\hline Q-value & $(0.234)$ & $(0.320)$ & $(0.248)$ & $(0.070)$ & $(0.512)$ & $(1.000)$ \\
\hline Control Mean & -0.435 & -0.555 & -0.264 & -0.330 & -0.410 & -0.564 \\
\hline \multicolumn{7}{|c|}{ Panel D: Free DFS Households (Baseline Anemic Only) } \\
\hline Household in Free DFS Treatment & $\begin{array}{l}-0.080 \\
{[0.072]}\end{array}$ & $\begin{array}{l}-0.096 \\
{[0.082]}\end{array}$ & $\begin{array}{l}-0.053 \\
{[0.115]}\end{array}$ & $\begin{array}{c}0.013 \\
{[0.150]}\end{array}$ & $\begin{array}{l}-0.149 \\
{[0.078]}\end{array}$ & $\begin{array}{l}-0.007 \\
{[0.130]}\end{array}$ \\
\hline Q-value & $(0.538)$ & $(0.325)$ & (1.000) & (1.000) & $(0.204)$ & (1.000) \\
\hline Control Mean & -0.487 & -0.558 & -0.330 & -0.337 & -0.433 & -0.661 \\
\hline Observations & 3443 & 2394 & 1046 & 454 & 2008 & 981 \\
\hline
\end{tabular}

1 Standard errors in brackets.

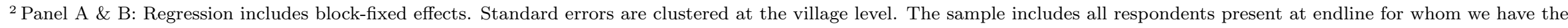
respective outcomes data, excluding Free DFS Households. Panel C \& D: Standard errors are cluster at the village level. The sample includes all respondents located in the Sales Experiment control group or Free DFS households, who were present at endline and for whom we have the respective outcomes data.

${ }^{3}$ Controls include the following variables from endline: Baseline Hemoglobin Concentration, Age, Age-Squared, a dummy for if the household split between baseline and endline, and

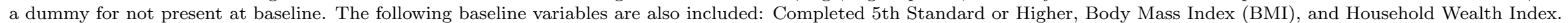
Note: For children under 10 , education is for the head of the household. 
Table A7c: Health Outcomes - Standardized Mental Health (Baseline Respondents Only)

\begin{tabular}{|c|c|c|c|c|c|c|}
\hline Sample: & $\begin{array}{l}(1) \\
\text { All }\end{array}$ & $\begin{array}{c}(2) \\
\text { Female }\end{array}$ & $\begin{array}{l}(3) \\
\text { Male }\end{array}$ & $\begin{array}{c}(4) \\
\text { Child }(<15 \text { years })\end{array}$ & $\begin{array}{c}(5) \\
\text { Adult (15-49 years) }\end{array}$ & $\begin{array}{l}(6) \\
\text { Elderly }(50+\text { years })\end{array}$ \\
\hline \multicolumn{7}{|l|}{ Panel A: Sales Experiment } \\
\hline$\overline{\text { Sales village }}$ & $\begin{array}{l}-0.001 \\
{[0.023]}\end{array}$ & $\begin{array}{c}0.019 \\
{[0.034]}\end{array}$ & $\begin{array}{l}-0.030 \\
{[0.023]}\end{array}$ & $\begin{array}{l}-0.086 \\
{[0.048]}\end{array}$ & $\begin{array}{c}0.011 \\
{[0.025]}\end{array}$ & $\begin{array}{c}0.021 \\
{[0.033]}\end{array}$ \\
\hline Q-value & $(1.000)$ & $(1.000)$ & $(0.470)$ & $(0.287)$ & $(1.000)$ & $(1.000)$ \\
\hline Control Mean & -0.099 & -0.330 & 0.170 & -0.165 & -0.001 & -0.268 \\
\hline Observations & 24885 & 13341 & 11513 & 4447 & 14145 & 6292 \\
\hline \multicolumn{7}{|c|}{ Panel B: Sales Experiment (Baseline Anemic Only) } \\
\hline Sales village & $\begin{array}{c}0.016 \\
{[0.032]}\end{array}$ & $\begin{array}{c}0.036 \\
{[0.040]}\end{array}$ & $\begin{array}{l}-0.021 \\
{[0.036]}\end{array}$ & $\begin{array}{l}-0.084 \\
{[0.076]}\end{array}$ & $\begin{array}{c}0.041 \\
{[0.036]}\end{array}$ & $\begin{array}{c}0.014 \\
{[0.042]}\end{array}$ \\
\hline Q-value & $(1.000)$ & $(1.000)$ & $(1.000)$ & $(1.000)$ & $(1.000)$ & $(1.000)$ \\
\hline Control Mean & -0.194 & -0.361 & 0.123 & -0.176 & -0.108 & -0.339 \\
\hline Observations & 9975 & 6567 & 3394 & 1431 & 5302 & 3242 \\
\hline \multicolumn{7}{|l|}{ Panel C: Free DFS Households } \\
\hline Household in Free DFS Treatment & $\begin{array}{c}0.003 \\
{[0.042]}\end{array}$ & $\begin{array}{c}0.034 \\
{[0.057]}\end{array}$ & $\begin{array}{l}-0.044 \\
{[0.042]}\end{array}$ & $\begin{array}{l}-0.023 \\
{[0.083]}\end{array}$ & $\begin{array}{c}0.012 \\
{[0.047]}\end{array}$ & $\begin{array}{l}-0.018 \\
{[0.060]}\end{array}$ \\
\hline Q-value & $(0.453)$ & $(0.410)$ & $(0.248)$ & $(1.000)$ & $(0.512)$ & $(1.000)$ \\
\hline Control Mean & -0.099 & -0.330 & 0.170 & -0.165 & -0.001 & -0.268 \\
\hline \multicolumn{7}{|c|}{ Panel D: Free DFS Households (Baseline Anemic Only) } \\
\hline Household in Free DFS Treatment & $\begin{array}{c}0.026 \\
{[0.057]}\end{array}$ & $\begin{array}{c}0.035 \\
{[0.068]}\end{array}$ & $\begin{array}{l}-0.002 \\
{[0.066]}\end{array}$ & $\begin{array}{c}0.102 \\
{[0.115]}\end{array}$ & $\begin{array}{c}0.012 \\
{[0.068]}\end{array}$ & $\begin{array}{l}-0.024 \\
{[0.075]}\end{array}$ \\
\hline Q-value & $(0.681)$ & $(0.581)$ & (1.000) & (1.000) & $(0.401)$ & (1.000) \\
\hline Control Mean & -0.194 & -0.361 & 0.123 & -0.176 & -0.108 & -0.339 \\
\hline Observations & 5697 & 3734 & 1955 & 803 & 3018 & 1876 \\
\hline
\end{tabular}

1 Standard errors in brackets.

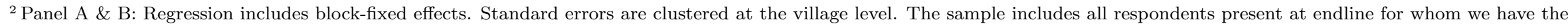
respective outcomes data, excluding Free DFS Households. Panel C \& D: Standard errors are cluster at the village level. The sample includes all respondents located in the Sales Experiment control group or Free DFS households, who were present at endline and for whom we have the respective outcomes data.

${ }^{3}$ Controls include the following variables from endline: Baseline Hemoglobin Concentration, Age, Age-Squared, a dummy for if the household split between baseline and endline, and

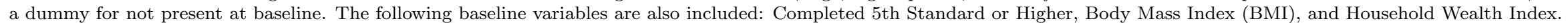
Note: For children under 10, education is for the head of the household. 
Table A8: Adolescent (13-17 years) Estimates (Baseline Respondents Only)

\begin{tabular}{|c|c|c|c|c|}
\hline \multirow[b]{3}{*}{ Sample: } & \multicolumn{2}{|c|}{ Hemoglobin Concentration } & \multicolumn{2}{|c|}{ Anemia } \\
\hline & $(1)$ & $(2)$ & $(3)$ & $(4)$ \\
\hline & Adolescents & Anemic Adolescents & Adolescents & Anemic Adolescents \\
\hline \multicolumn{5}{|l|}{ Panel A: - Sales Experiment (OLS) } \\
\hline \multirow[t]{2}{*}{ Sales village } & 0.045 & 0.151 & 0.004 & -0.024 \\
\hline & {$[0.056]$} & {$[0.096]$} & {$[0.018]$} & {$[0.028]$} \\
\hline Q-value & $(0.411)$ & $(0.211)$ & $(1.000)$ & $(1.000)$ \\
\hline Observations & 3551 & 1276 & 3551 & 1276 \\
\hline \multicolumn{5}{|c|}{ Panel B: Free DFS Experiment Compared to Control (OLS) } \\
\hline \multirow[t]{2}{*}{ Household in Free DFS Treatment } & 0.156 & 0.071 & -0.053 & -0.000 \\
\hline & {$[0.107]$} & {$[0.176]$} & {$[0.027]$} & {$[0.040]$} \\
\hline Q-value & $(0.159)$ & $(1.000)$ & $(0.252)$ & $(1.000)$ \\
\hline Observations & 2185 & 792 & 2185 & 792 \\
\hline \multicolumn{5}{|c|}{ Panel C: Free DFS Experiment within Free DFS Villages (OLS) } \\
\hline Household in Free DFS Treatment & 0.066 & -0.096 & -0.052 & -0.001 \\
\hline Q-value & $(1.000)$ & $(1.000)$ & $(1.000)$ & $(1.000)$ \\
\hline Observations & 636 & 238 & 636 & 238 \\
\hline \multicolumn{5}{|l|}{ Panel D: 2SLS Estimates } \\
\hline \multirow[t]{2}{*}{ Currently Using or Penultimately Used DFS } & 0.425 & 0.211 & -0.102 & 0.020 \\
\hline & {$[0.181]$} & {$[0.305]$} & {$[0.049]$} & {$[0.069]$} \\
\hline Control Mean & 12.398 & 11.644 & 0.461 & 0.636 \\
\hline Observations & 2341 & 849 & 2341 & 849 \\
\hline
\end{tabular}

${ }^{1}$ Standard errors in brackets.

${ }^{2}$ Panel A: Regression includes block-fixed effects. Standard errors are clustered at the village level. The sample includes all respondents present at endline for whom we have the respective outcomes data, excluding Free DFS Households. Panel B: Standard errors are cluster at the village level. The sample includes all respondents located in the Sales Experiment control group or Free DFS households, who were present at endline and for whom we have the respective outcomes data. Panel C: Regression includes village fixed effects. Standard errors are clustered at the household level. The sample includes all respondents located in the villages where the Free DFS experiment took place, who were present at endline and for whom we have the respective outcomes data. Panel D: Standard errors are clustered at the village level and the regression includes all respondents who were present at endline and for whom we have the respective outcomes data. Currently using DFS or Penultimately Used DFS is instrumented by a dummy for Sales Experiment and a dummy for Free DFS Households

${ }^{3}$ Controls include the following variables from endline: Baseline Hemoglobin Concentration, Age, Age-Squared, a dummy for if the household split between baseline and endline, and a dummy for not present at baseline. The following baseline variables are also included: Completed 5th Standard or Higher, Body Mass Index (BMI), and Household Wealth Index. Note: For children under 10, education is for the head of the household.

${ }^{4}$ Anemia thresholds are determined by age and gender, therefore, a dummy for each of these age groups is included in the regressions for anemia. 